\title{
Multivariate analysis of infant death in \\ England and Wales in \\ 2005-06, with focus on \\ socio-economic status \\ and deprivation
}

Laura Oakley, Noreen Maconochie and Pat Doyle

London School of Hygiene and

Tropical Medicine

Nirupa Dattani and Kath Moser

Office for National Statistics

Current health inequality targets include the goal of reducing the differential in infant mortality between social groups. This article reports on a multivariate analysis of risk factors for infant mortality, with specific focus on deprivation and socio-economic status. Data on all singleton live births in England and Wales in 2005-06 were used and deprivation quintile (Carstairs index) was assigned to each birth using postcode at birth registration. Deprivation had a strong independent effect on infant mortality, risk of death tending to increase with increasing levels of deprivation. The strength of this relationship depended, however, on whether the babies were low birthweight, preterm or small-for-gestational-age. Trends of increasing mortality risk with increasing deprivation were strongest in the postneonatal period. Uniquely, this article reports the number and proportion of all infant deaths which would potentially be avoided if all levels of deprivation were reduced to that of the least deprived group. It estimates that one quarter of all infant deaths would potentially be avoided if deprivation levels were reduced in this way.

\section{Introduction}

There are many established risk factors for infant mortality; prematurity, ${ }^{1}$ low birthweight ${ }^{2}$ and multiplicity ${ }^{3}$ being the most significant in terms of strength of association and consistency. Risk factors are known to vary according to age at death. For example, the effect of low birthweight and prematurity is stronger in the neonatal period than the postneonatal period. ${ }^{4}$

Socio-economic status is strongly associated with deaths under one year, with a clear trend observed for increased mortality among births occurring to more socially disadvantaged mothers. In 2007, infants of fathers in the routine occupations class had an infant mortality rate of 5.8 per 1,000 live births compared with a rate of 2.8 per 1,000 live births among infants born to fathers in the large employers and higher managerial occupations class. ${ }^{5}$ Social inequalities in health are a key public health focus. Public Service Agreement (PSA) targets set in 2001 and updated in 2004, to be achieved by 2010 , include the goal of reducing the gap between the infant mortality rate for the routine and manual class and the rate for the population as a whole by at least 10 per cent. $^{6}$

Social class derived from father's occupation is a frequently used indicator of socio-economic status and the indicator used in the setting of the PSA target. However, it is not the only indicator of socio-economic status available. Deprivation indices, such as Carstairs scores are area-based measures of economic and social deprivation and have been used as another indicator of socio-economic status. Deprivation indices are subject to the usual limitations of ecological summary measures, but may provide a measure of socio-economic status where other indicators are unreliable or unavailable. An advantage of area-based measures is that they are not reliant on the 
availability of individual data. This is a particular issue with the National Statistics Socio-economic Classification (NS-SEC), as sole registered births (births occurring outside marriage, registered by the mother alone) are not coded to NS-SEC because father's occupation is not available. In addition, only a 10 per cent sample of live birth records (which have occurred inside marriage or jointly registered by both parents) are coded to NS-SEC.

Previous studies have used deprivation indices to investigate the role of deprivation in infant mortality, observing similar trends to occupational social class. ${ }^{7,8,9}$ The literature on the relationship between social class and deprivation indices is mixed, with some authors suggesting that deprivation indices can be used as a proxy for social class, and other authors expressing caution and suggesting that area-based deprivation has an independent effect on mortality.

National infant mortality rates have previously been investigated with respect to important risk factors such as multiplicity, sex, mother's age, marital status/type of registration and parity inside marriage and the results presented separately for each risk factor in turn, ${ }^{10}$ but little work has been conducted using multivariate analysis. The recent exception to this was an analysis of risk factors for neonatal mortality among singleton infants weighing 2,500-5,499 grams. ${ }^{11}$ This analysis found that even after excluding low birthweight babies, birthweight was still the strongest risk factor for neonatal mortality. Sex and older maternal age both remained independently associated with neonatal mortality in this sample after adjustment for other factors.

Recent methodological improvements have provided useful opportunities for the investigation of infant mortality in England and Wales. The introduction of the NHS Numbers for Babies (NN4B) programme in 2005 (when NHS numbers began to be allocated at birth) has enabled the linkage of key variables (such as gestation and ethnicity of the infant) to birth registration records. Information on these variables is not collected at live birth registration, and so previously these data have been unavailable for analysis (and were not included in the multivariate analysis quoted earlier ${ }^{11}$ ).

In this article we report our investigation into risk factors for infant mortality in England and Wales in 2005-06, focusing on the contribution of socio-economic status and deprivation.

\section{Methods}

\section{Source data}

Data on all live births that occurred in England and Wales in 2005 and 2006 were extracted from birth registration records linked to the corresponding NN4B record. A detailed description of this linkage process as applied to births occurring in the first quarter of 2005 is reported in an earlier Health Statistics Quarterly article. ${ }^{12}$

For births which had resulted in infant death, further details of timing and cause of death were obtained by linkage to death registration records. Details on this linkage have been published previously. ${ }^{13}$ The data extract was taken in mid-2008 to ensure the inclusion of all late birth and death registrations. Multiple births were excluded from the data extract prior to the main analysis, since risk factors for mortality are likely to differ substantially for these births.

\section{Variables available for analysis}

Socio-economic status: NS-SEC and deprivation index

The role of social inequalities in infant mortality was a key focus of this investigation. NS-SEC replaced previously-used classifications of Social Class and Socio-economic Groups in 2001, and represents the current system of allocating socio-economic status to reported occupational position. A detailed description of NS-SEC is published on the Office for National Statistics (ONS) website. ${ }^{14}$ The principal version of NS-SEC is an eight or nine group analytic version, collapsible to five or three group versions (Box One). The analysis reported here uses the three class version of NS-SEC, as this includes the routine and manual group which was used in the setting of the PSA target on infant mortality. Parental occupation is recorded at birth and death registration, but only NS-SEC status coded at birth registration was used for this analysis. However, since NS-SEC status was missing for over 90 per cent of the data (being only available for a 10 per cent sample of married/jointly registered births and not present at all for sole registrations) most analyses in this paper did not concentrate on this measure of socio-economic status.

\section{Box one}

\section{National Statistics Socio-economic Classification}

\begin{tabular}{|c|c|c|}
\hline Principal version & 5 group version & 3 group version \\
\hline $\begin{array}{l}1.1 \text { Large employers } \\
\text { and higher managerial } \\
\text { occupations }\end{array}$ & \multirow{3}{*}{$\begin{array}{l}1 \text { Managerial and } \\
\text { professional occupations }\end{array}$} & \multirow{3}{*}{$\begin{array}{l}1 \text { Managerial and } \\
\text { professional occupations }\end{array}$} \\
\hline $\begin{array}{l}1.2 \text { Higher professional } \\
\text { occupations }\end{array}$ & & \\
\hline $\begin{array}{l}2 \text { Lower managerial and } \\
\text { professional occupations }\end{array}$ & & \\
\hline $\begin{array}{l}3 \text { Intermediate } \\
\text { occupations }\end{array}$ & $\begin{array}{l}2 \text { Intermediate } \\
\text { occupations }\end{array}$ & \multirow{2}{*}{$\begin{array}{l}2 \text { Intermediate } \\
\text { occupations }\end{array}$} \\
\hline $\begin{array}{l}4 \text { Small employers and } \\
\text { own account workers }\end{array}$ & $\begin{array}{l}3 \text { Small employers and } \\
\text { own account workers }\end{array}$ & \\
\hline $\begin{array}{l}5 \text { Lower supervisory and } \\
\text { technical occupations }\end{array}$ & $\begin{array}{l}4 \text { Lower supervisory and } \\
\text { technical occupations }\end{array}$ & \multirow{3}{*}{$\begin{array}{l}3 \text { Routine and manual } \\
\text { occupations }\end{array}$} \\
\hline $\begin{array}{l}6 \text { Semi-routine } \\
\text { occupations }\end{array}$ & \multirow{2}{*}{$\begin{array}{l}5 \text { Semi-routine and } \\
\text { routine occupations }\end{array}$} & \\
\hline 7 Routine occupations & & \\
\hline $\begin{array}{l}8 \text { Never worked and } \\
\text { long-term unemployed }\end{array}$ & $\begin{array}{l}\text { Never worked and } \\
\text { long-term unemployed }\end{array}$ & $\begin{array}{l}\text { Never worked and } \\
\text { long-term unemployed }\end{array}$ \\
\hline
\end{tabular}

The Carstairs deprivation index was used to assign a deprivation score to all births, according to the postcode given at birth registration. This deprivation index was chosen as it is frequently used for other ONS health-related analyses and correlates well with other deprivation indices. A full description of how Carstairs scores are calculated is in an earlier article. ${ }^{15}$ Briefly, Carstairs scores are based on the un-weighted combination of four variables from the 2001 Census (unemployment, overcrowding, car ownership and low social class) (Box Two), and are assigned to the postcode. The Carstairs index is thus an ecological (rather than individual) based measure, since postcodes only identify the address to within an average of 15 properties per postcode (and can be up to 100 properties). The Carstairs scores for the total (all ages) population can be used to rank electoral wards from the least to the most deprived and divided into percentile groups. For this analysis electoral wards were divided into quintiles (equal fifths) of deprivation using 2001 experimental ward total population estimates. Since these quintiles are based on the total (all age) population, numbers of live births within each Carstairs deprivation group in this analysis will not be equal. 


\section{Box two}

\section{Census variables used in the calculation of the Carstairs deprivation index}

Unemployment: unemployed males 16 and over as a proportion of all economically active males aged 16 and over

Overcrowding: persons in households with one or more persons per room as a proportion of all residents in households

Car ownership: residents in households with no car as a proportion of all residents in households

Low Social Class: residents in households with an economically active head of household in Social Class IV or V approximated from NS-SEC as a proportion

\section{Other social and biological risk factors}

The following information was taken from birth registration records: maternal age at birth, maternal country of birth, birthweight of infant, year of birth of infant and sex of infant. Parity of the mother was available from birth registration records but was excluded as it only refers to parity within marriage and is therefore not a reliable indicator of 'true' parity. The ethnicity of the infant (as defined by the mother using pre-specified categories) was taken from NN4B data, along with gestational age at birth. A composite variable incorporating maternal country of birth (UK versus non-UK) and infant's ethnicity (collapsed into four categories: Asian, Black, White, Other) was also created. Sex-standardised birthweight for gestational age was calculated using within-cohort gestation- and sex-specific centiles. Infants with birthweights below the 5th centile were classified as 'small-for-gestational-age'.

\section{Classification of infant deaths}

Timing of death was classified as early neonatal, late neonatal, or postneonatal, according to established definitions (Box Three). Causes of death were grouped using ONS cause groups, ${ }^{16}$ based on the established Wigglesworth classification system. Deaths were classified according to causes occurring before the onset of labour (congenital anomalies, antepartum infections, or immaturity related conditions), in or shortly after labour (asphyxia, anoxia or intrapartum trauma), postnatally (other specific conditions, sudden infant deaths), and other (other conditions not mentioned above).

\section{Box three}

\section{Definitions used in this paper}

Early neonatal deaths: deaths at ages under 7 days Late neonatal deaths: deaths at ages 7 days and over but under 28 days Neonatal deaths: deaths at ages under 28 days

Postneonatal deaths: deaths at ages 28 days and over but under one year Infant deaths: deaths under one year

Early neonatal mortality rate: early neonatal deaths per 1,000 live births Late neonatal mortality rate: late neonatal deaths per 1,000 live births surviving the early neonatal period

Neonatal mortality rate: neonatal deaths per 1,000 live births

Postneonatal mortality rate: postneonatal deaths per 1,000 live births surviving the neonatal period

Infant mortality rate: infant deaths per 1,000 live births

\section{Statistical analysis}

All analyses in this paper were performed using Stata statistical software (version 10, Stata Corp, College Station, TX, USA). All P-values quoted are two-sided and values less than 0.05 have been taken to indicate statistical significance.

Mortality rates were calculated using the number of infants still alive and at risk at the beginning of each time period (Box Three).

The multivariate analysis followed a strategy which included consideration of both plausible confounding (Box Four) and potential causal pathways. Carstairs deprivation indices and (among the 10 per cent sample where this was coded) NS-SEC were considered to be the main factors of interest in this analysis, with maternal age, marital/registration status, maternal country of birth, and sex and ethnicity of the baby being considered as potential confounding variables.

\section{Box four}

\section{Confounding and Interaction}

Confounding is the situation where an association between an exposure and an outcome is entirely or partially due to another exposure (called the confounder). A variable will only confound an association if it satisfies three conditions:

- It must be associated with the exposure of interest

- It must be a risk factor for the outcome of interest

- It must not be on the causal pathway (be an intervening or mediating variable) between the exposure of interest and the outcome of interest

An example is the finding that coffee drinking is associated with risk of coronary heart disease (CHD). In fact coffee drinking is not a risk factor for $\mathrm{CHD}$, but the observation is driven by the fact that people who drink coffee are more likely to smoke than people who do not drink coffee. When the data are analysed separately for smokers and non-smokers (stratified by smoking status) we find that coffee drinking is not, in itself, a risk factor. This is an example of complete confounding, but most examples are of partial confounding.

There are several ways of making adjustments for confounding effects, and all involve the stratification of data according to different levels of the potential confounding factor. It is important to note that in confounding, the two factors (the exposure of interest and the potential confounder) are associated with each other (for example, coffee drinkers are more likely to smoke than non-coffee drinkers) but do not act together -or rely on each other - to produce an effect. They act independently.

Interaction (or effect modification) is an effect of two exposures (or risk factors) on an outcome, where the effects are not independent. They act together to produce an effect on the outcome which is different than the effect of each factor separately. In this situation it is not possible to 'adjust' for one of the factors, and the results must be presented separately for different levels of the effect modifier. 
Analyses were conducted separately for neonatal, postneonatal and total infant mortality. The association between mortality and deprivation, controlling for confounding, was explored using logistic regression analysis, effects on risk being estimated by odds ratios (OR) with 95 per cent confidence intervals (CI), and statistical significance being tested using likelihood ratio tests. ${ }^{17}$ The odds ratios are sometimes referred to as generic 'relative risks' in the text.

The association between deprivation and socio-economic status and infant mortality in relation to the more 'proximal' factors (along the causal pathway) of gestation and birthweight (and sex-standardised weight for gestation) was explored further by examining interaction terms in the models (Box Four). To maximise statistical power, interaction terms with Carstairs index or NS-SEC were calculated using a dichotomised version of the potential modifying variable (for example, interaction of deprivation with birthweight: 10 categories, 5 deprivation quintiles, and two birthweight categories $(<2,500$ grams, 2,500 grams and over). Since there is substantial overlap between preterm delivery, low birthweight and small-for-gestational-age, these three factors could only be considered in separate analyses. Stratified measures of effect were reported when statistically significant interactions were found.

Although NS-SEC is the variable most relevant to the PSA target, the small proportion of births coded to NS-SEC, together with the exclusion of sole registrations from the coding led to conducting the majority of the analyses using deprivation as the main factor of interest. An analysis of the interrelationship between NS-SEC and Carstairs deprivation among the 10 per cent sample of births where the parents were married or jointly registered the birth was included in order to test the validity of this decision.

Population excess (or attributable) deaths and population excess (or attributable) deaths per cent were calculated using adjusted odds ratios (Box Five). These measure the number and proportion of deaths in the population that would potentially be avoided if the risk in the 'exposed'

\section{Box five}

\section{Calculation of Population Excess Deaths (Population Attributable Risk) and Population Excess Deaths per cent (Population Attributable Risk Fraction)}

Population excess per cent, also called the population attributable risk fraction, refers to the proportion of deaths in a population that can be attributed to an exposure, and is the proportion of deaths that could theoretically be saved or avoided in the population if the exposure was removed. There are several ways of calculating this, but in this paper the following were used:

(i) Where there are two strata only (exposed and unexposed):

$p(R R-1) /(R R-1)+1$

where $p=$ proportion of population exposed, and RR is the adjusted relative risk between exposure and outcome. Odds Ratios are used to estimate the relative risk

(ii) Where there were more than two strata:

$p_{i}\left(R R_{i}-1\right) / R R_{i}$

where i refers to each stratum, and $p_{i}=$ proportion of 'exposed' (in groups above the baseline category) deaths in stratum i

Population excess deaths refer to the number of deaths that can be attributed to a factor, and that theoretically could be 'saved' or 'avoided' if the factor was removed from the population. In this paper these were calculated as the total number of deaths within the population (or stratum) multiplied by the population (or stratum) excess per cent. group was the same as that in the baseline or 'unexposed' group. It should be emphasised that this is a theoretical construct and is used in this work for illustrative purposes only.

\section{Results}

Overall there were 1,315,352 live births that occurred in 2005 and 2006 and were registered in England and Wales, 3 per cent $(39,154)$ of which were multiple births. All but 1,387 of these births ( 0.1 per cent $)$ were successfully linked to the corresponding NN4B birth record. Among these births, 6,491 were registered as infant deaths (3,444 early neonatal, 1,099 late neonatal and 1,948 postneonatal deaths). Mortality rates were higher among multiple births, with an infant mortality rate of 23.5 per 1,000 live births compared with 4.4 per 1,000 live births for singleton births. Early neonatal mortality was particularly high among multiple births compared to singletons (14.4 compared with 2.3 per 1,000 live births). Multiple births were excluded from all further analyses, as their risk profile is likely to differ substantially from that of singleton babies.

\section{Descriptive analyses}

A description of infant mortality rates by year of death and the available social and biological risk factors is presented in Table 1. Among 1,276,198 singleton live births registered in 2005-06 there were a total of 5,571 infant deaths, giving an overall infant mortality rate of 4.4 per 1,000 live births. There was no difference in infant mortality between 2005 and 2006.

Death rates were more than twice as high in the first 28 days of life as in the subsequent 11 months. There were marked trends of increasing mortality with increasing deprivation (all babies) and increasing mortality with declining social class as measured by NS-SEC (among the subset for which this was coded).

Babies born to married parents had the lowest infant mortality, with the highest risks observed among babies registered by parents living at different addresses and those where the birth was registered by the mother alone (sole registrations).

Infants born to mothers who were born outside the UK had higher risks than those born to UK-born mothers. Non-White babies had higher mortality rates than White babies, particularly those classified as Asian or Black. Interestingly, within each ethnic group mortality was lower among those born to non-UK-born mothers, the only exception being White babies in the neonatal period, where the rates were the same.

There was a u-shaped relationship between mortality and maternal age, more marked in the neonatal period, with the lowest risk among babies whose mothers were aged 30-34 at birth.

With regard to the characteristics of the babies themselves, males had around 20 per cent higher mortality than females. Highest mortality rates were observed among preterm infants with rates declining dramatically with increasing gestational age: among preterm infants the rates ranged from 372.9 to 6.5 deaths per 1,000 in the neonatal period, and from 81.1 to 4.4 deaths per 1,000 in the postneonatal period, the rates then reducing to under 1 per 1,000 in both periods for babies born at 37 weeks and over.

A similar pattern was observed for low birthweight babies compared with those weighing 2,500 grams or more, the rates reducing from 170.6 and 7.6 per 1,000 live births (neonatal period) and 38.9 and 5.3 per 1,000 (postneonatal period) among extremely and very low birthweight babies respectively, to under 1 per 1,000 in both periods for babies weighing 2,500 grams or more.

Similarly, babies whose weight was below the 5 per cent centile of sex-specific weight-for-gestation had infant mortality rates that were almost 3.5 times those of babies at or above the 5 th centile. The neonatal mortality rate for small-for-gestational-age babies was 3.2 times, and the postneonatal mortality rate 4 times, that for non-small-for-gestational-age babies. 
Table 1 Singleton neonatal, postneonatal and infant deaths (numbers and rates) by social and biological risk factors, 2005-06

England and Wales

\begin{tabular}{|c|c|c|c|c|c|c|c|c|}
\hline & & \multicolumn{4}{|c|}{ Numbers } & \multirow{2}{*}{\multicolumn{3}{|c|}{ Rates }} \\
\hline & & \multirow{2}{*}{ Live births } & \multicolumn{3}{|c|}{ Deaths } & & & \\
\hline & & & Neonatal & Postneonatal & Infant & Neonatal $^{1}$ & Postneonatal $^{2}$ & Infant $^{1}$ \\
\hline Total & & $1,276,198$ & 3,797 & 1,774 & 5,571 & 3.0 & 1.4 & 4.4 \\
\hline \multirow[t]{2}{*}{ Year } & 2005 & 626,917 & 1,875 & 867 & 2,742 & 3.0 & 1.4 & 4.4 \\
\hline & 2006 & 649,281 & 1,922 & 907 & 2,829 & 3.0 & 1.4 & 4.4 \\
\hline \multirow[t]{6}{*}{ Carstairs deprivation index } & 1 (least deprived) & 199,540 & 399 & 176 & 575 & 2.0 & 0.9 & 2.9 \\
\hline & 2 & 213,613 & 488 & 222 & 710 & 2.3 & 1.0 & 3.3 \\
\hline & 3 & 239,341 & 619 & 279 & 898 & 2.6 & 1.2 & 3.8 \\
\hline & 4 & 276,132 & 891 & 416 & 1,307 & 3.2 & 1.5 & 4.7 \\
\hline & 5 (most deprived) & 347,182 & 1,387 & 676 & 2,063 & 4.0 & 2.0 & 5.9 \\
\hline & Missing & 390 & 13 & 5 & 18 & 33.3 & 13.3 & 46.2 \\
\hline \multirow[t]{5}{*}{ NS-SEC } & Higher and professional & 44,651 & 100 & 33 & 133 & 2.2 & 0.7 & 3.0 \\
\hline & Intermediate & 23,103 & 54 & 30 & 84 & 2.3 & 1.3 & 3.6 \\
\hline & Routine and manual & 44,136 & 152 & 56 & 208 & 3.4 & 1.3 & 4.7 \\
\hline & Other (unemployed/students/ns) & 7,234 & 35 & 14 & 49 & 4.8 & 1.9 & 6.8 \\
\hline & Missing & $1,157,074$ & 3,456 & 1,641 & 5,097 & 3.0 & 1.4 & 4.4 \\
\hline \multirow[t]{4}{*}{ Registration type/Marital status } & Married & 722,871 & 1,895 & 840 & 2,735 & 2.6 & 1.2 & 3.8 \\
\hline & Sole registration ${ }^{3}$ & 88,242 & 309 & 243 & 552 & 3.5 & 2.8 & 6.3 \\
\hline & Joint registration/same address ${ }^{4}$ & 351,429 & 1,147 & 461 & 1,608 & 3.3 & 1.3 & 4.6 \\
\hline & Joint registration/different address ${ }^{4}$ & 113,656 & 446 & 230 & 676 & 3.9 & 2.0 & 5.9 \\
\hline \multirow[t]{6}{*}{ Maternal age (years) } & $<20$ & 89,108 & 353 & 200 & 553 & 4.0 & 2.3 & 6.2 \\
\hline & $20-24$ & 245,328 & 795 & 469 & 1,264 & 3.2 & 1.9 & 5.2 \\
\hline & $25-29$ & 328,102 & 1,014 & 411 & 1,425 & 3.1 & 1.3 & 4.3 \\
\hline & $30-34$ & 364,249 & 914 & 374 & 1,288 & 2.5 & 1.0 & 3.5 \\
\hline & $35-39$ & 205,633 & 559 & 263 & 822 & 2.7 & 1.3 & 4.0 \\
\hline & 40 and over & 43,777 & 162 & 57 & 219 & 3.7 & 1.3 & 5.0 \\
\hline \multirow[t]{2}{*}{ Maternal country of birth } & UK & $1,002,722$ & 2,827 & 1,368 & 4,195 & 2.8 & 1.4 & 4.2 \\
\hline & non-UK & 273,439 & 969 & 406 & 1,375 & 3.5 & 1.5 & 5.0 \\
\hline \multirow[t]{2}{*}{ Sex of baby } & Male & 653,362 & 2,127 & 1,002 & 3,129 & 3.3 & 1.5 & 4.8 \\
\hline & Female & 622,836 & 1,670 & 772 & 2,442 & 2.7 & 1.2 & 3.9 \\
\hline \multirow[t]{5}{*}{ Ethnicity of baby } & White & 889,241 & 2,265 & 1,125 & 3,390 & 2.5 & 1.3 & 3.8 \\
\hline & Asian & 96,908 & 433 & 228 & 661 & 4.5 & 2.4 & 6.8 \\
\hline & Black & 53,999 & 273 & 98 & 371 & 5.1 & 1.8 & 6.9 \\
\hline & Other & 102,133 & 348 & 160 & 508 & 3.4 & 1.6 & 5.0 \\
\hline & Missing & 133,917 & 478 & 326 & 804 & 3.6 & 2.4 & 6.0 \\
\hline \multirow[t]{9}{*}{ Baby's ethnicity and maternal country of birth } & White, UK born & 812,702 & 2,072 & 1,056 & 3,128 & 2.5 & 1.3 & 3.8 \\
\hline & White, non-UK born & 76,517 & 193 & 69 & 262 & 2.5 & 0.9 & 3.4 \\
\hline & Asian, UK born & 32,203 & 161 & 84 & 245 & 5.0 & 2.6 & 7.6 \\
\hline & Asian, non-UK born & 64,700 & 272 & 144 & 416 & 4.2 & 2.2 & 6.4 \\
\hline & Black, UK born & 11,992 & 67 & 26 & 93 & 5.6 & 2.2 & 7.8 \\
\hline & Black, non-UK born & 42,004 & 206 & 72 & 278 & 4.9 & 1.7 & 6.6 \\
\hline & Other, UK born & 42,093 & 165 & 74 & 239 & 3.9 & 1.8 & 5.7 \\
\hline & Other, non-UK born & 60,037 & 182 & 86 & 268 & 3.0 & 1.4 & 4.5 \\
\hline & Missing (not stated/not linked) & 133,950 & 479 & 163 & 642 & 3.6 & 1.2 & 4.8 \\
\hline \multirow[t]{6}{*}{ Gestation (weeks) } & $21-27$ & 4,934 & 1,840 & 251 & 2,091 & 372.9 & 81.1 & 423.8 \\
\hline & $28-31$ & 8,866 & 335 & 132 & 467 & 37.8 & 15.5 & 52.7 \\
\hline & $32-36$ & 64,330 & 418 & 280 & 698 & 6.5 & 4.4 & 10.9 \\
\hline & $37-41$ & $1,131,844$ & 1,027 & 1,045 & 2,072 & 0.9 & 0.9 & 1.8 \\
\hline & 42 and over & 56,260 & 52 & 46 & 98 & 0.9 & 0.8 & 1.7 \\
\hline & Missing & 9,964 & 125 & 20 & 145 & 12.5 & 2.0 & 14.6 \\
\hline \multirow[t]{5}{*}{ Birthweight (grams) } & $<1,500$ & 12,132 & 2,070 & 391 & 2,461 & 170.6 & 38.9 & 202.9 \\
\hline & $1,500-2,499$ & 65,050 & 497 & 341 & 838 & 7.6 & 5.3 & 12.9 \\
\hline & $2,500-4,499$ & $1,169,415$ & 1,034 & 1,017 & 2,051 & 0.9 & 0.9 & 1.8 \\
\hline & 4,500 and over & 21,709 & 19 & 10 & 29 & 0.9 & 0.5 & 1.3 \\
\hline & Missing & 7,892 & 177 & 15 & 192 & 22.4 & 1.9 & 24.3 \\
\hline Small for gestational age & SGA $(<5 \%)$ & 62,136 & 478 & 295 & 773 & 7.7 & 4.8 & 12.4 \\
\hline & Not SGA $(\geq 5 \%)$ & $1,203,756$ & 2,860 & 1,459 & 4,316 & 2.4 & 1.2 & 3.6 \\
\hline & Missing & 10,306 & 462 & 20 & 482 & 44.8 & 2.0 & 46.8 \\
\hline
\end{tabular}

1 Neonatal and infant mortality rates are given per 1,000 live births.

2 Postneonatal mortality rates are given per 1,000 live births surviving the neonatal period.

3 Birth takes place outside marriage, only mother registers the birth.

4 Birth takes place outside marriage, both mother and father register the birth. 
Mortality rates appeared high among those with missing information on gestation and birthweight. The reason for this is not known, but one possible explanation may be due to prioritising emergency/intensive care of high risk babies over recording data, particularly on the NN4B.

\section{Cause of death}

Immaturity-related conditions and congenital anomalies ( 42 per cent and 30 per cent of all infant deaths respectively) caused the largest numbers and rates of infant death (Table 2). In the neonatal period immaturity-related death predominated at 1.6 per 1,000 live births, with congenital anomalies accounting for a further 0.8 per 1,000 live births; these two causes accounted for 80 per cent of all neonatal deaths. In the postneonatal period congenital anomalies were the most common cause of death, 0.5 per 1,000 (36 per cent of all postneonatal death). Three other causes - immaturity, sudden infant death and other conditions - accounted for a further 41 per cent of deaths, each with a rate 0.2 per 1,000 (Table 2 ).

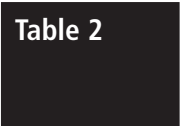

Singleton neonatal, postneonatal and infant deaths by cause of death and deprivation quintile, 2005-06

England and Wales

\begin{tabular}{l|l|l|l|l|l|l}
\hline \multirow{3}{*}{ Cause group } & \multicolumn{3}{|c|}{ Numbers } & \multicolumn{3}{c}{ Rates } \\
\cline { 2 - 5 } & \multicolumn{3}{|c|}{ Deaths } & \multicolumn{3}{c}{} \\
\cline { 2 - 6 } & Neonatal & Postneonatal & Infant & Neonatal $^{1}$ & Postneonatal $^{2}$ & Infant $^{1}$ \\
\hline
\end{tabular}

\section{Congenital}

1,008

anomalies

Antepartum

infections

Immaturity related

conditions

Asphyxia, anoxia or

trauma (intrapartum)

External conditions

Infections

Other specific

conditions

Sudden infant deaths

Other conditions

1,008

646

1,654

0.8

0.5

1.3

121

19

140

0.1

-

0.1

2,045

267

2,312

1.6

0.2

1.8

369

11

380

0.3

-

0.3

18

55

170

106

-

0.1

0.1

0.2

$21 \quad 39$

21
49

39

111

282

60

60
301

393

-

-

$0.2 \quad 0.2$

1 Neonatal and infant mortality rates are given per 1,000 live births.

2 Postneonatal mortality rates are given per 1,000 live births surviving the neonatal period.
Mortality from immaturity related conditions increased with increasing deprivation in both neonatal and postneonatal death periods, though this was more marked in the neonatal period (Figure 1). Conversely, trends for deaths from causes related to congenital anomalies were less marked with increasing deprivation in the neonatal period, but stronger in the postneonatal period. Death from antepartum infection and other conditions also showed strong trends with increasing deprivation in the neonatal period, but there were no other consistent trends in the first 28 days of life. In the postneonatal period mortality from sudden infant death increased markedly with increasing levels of deprivation, as did deaths from external factors, infections, and other causes.

\section{National Statistics Socio-economic Classification and Carstairs deprivation index}

Infant mortality rates by Carstairs classification and NS-SEC are presented in Table 3 for the 10 per cent sample of live births leading to infant deaths where NS-SEC was coded.

Overall, the mortality rates for NS-SEC and Carstairs deprivation index mapped well to each other (Table 3). The limitations of the ecological nature of the Carstairs measure are demonstrated in the body of the table, where it can be seen that within each (individually-coded) NS-SEC grouping there were births coded to all five deprivation categories, even in the highest (managerial and professional) group. The one exception to this was among babies of fathers who were unemployed or students (or no stated occupation), where there were no deaths and only 297 live births in the least deprived Carstairs category.

\section{Multivariate analysis}

Association between deprivation and co-variates (potential confounding variables and more proximal risk factors for infant mortality)

Maternal age, marital status/registration type, maternal country of birth and baby's ethnicity were all strongly related to Carstairs deprivation index (all $\mathrm{P}<0.001$ ). As levels of deprivation increased, mothers tended to be younger, less likely to be married or living with the father, and more likely to be non-UK-born. Babies who were Asian, Black or of other nonWhite ethnicity tended to have higher levels of deprivation.

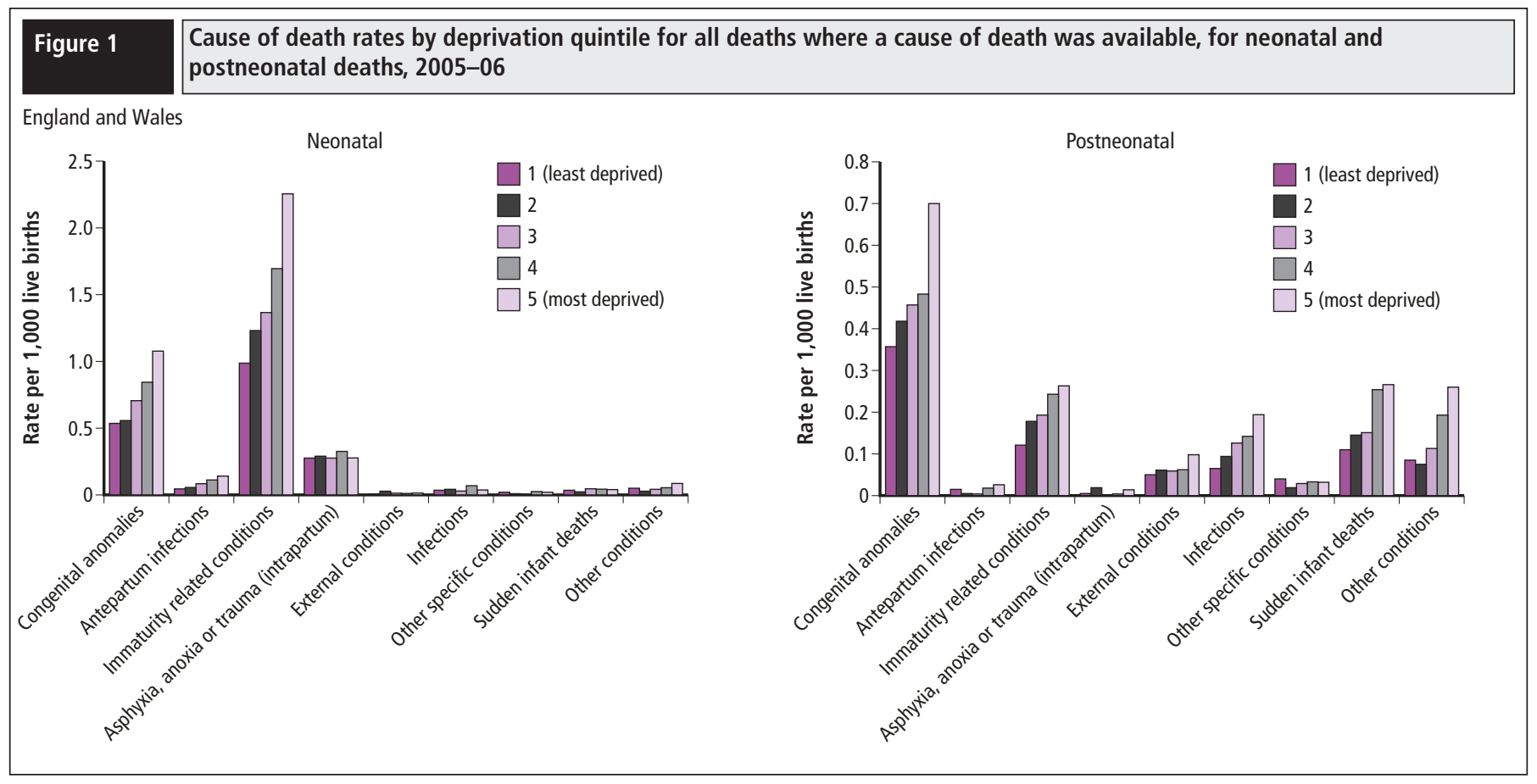


England and Wales

\begin{tabular}{|c|c|c|c|c|c|c|c|c|c|c|c|c|c|c|c|}
\hline \multirow{3}{*}{ Carstairs quintiles } & \multicolumn{12}{|c|}{ NS-SEC } & \multirow{2}{*}{\multicolumn{3}{|c|}{ All }} \\
\hline & \multicolumn{3}{|c|}{ Managerial and professional } & \multicolumn{3}{|c|}{ Intermediate } & \multicolumn{3}{|c|}{ Routine and manual } & \multicolumn{3}{|c|}{ Other } & & & \\
\hline & Neonatal ${ }^{1}$ & $\begin{array}{c}\text { Post- } \\
\text { neonatal }^{2}\end{array}$ & Infant $^{1}$ & Neonatal ${ }^{1}$ & $\begin{array}{c}\text { Post- } \\
\text { neonatal }^{2}\end{array}$ & Infant ${ }^{1}$ & Neonatal ${ }^{1}$ & $\begin{array}{c}\text { Post- } \\
\text { neonatal }\end{array}$ & Infant $^{1}$ & Neonatal ${ }^{1}$ & $\begin{array}{c}\text { Post- } \\
\text { neonatal }\end{array}$ & Infant $^{1}$ & Neonatal ${ }^{1}$ & $\begin{array}{c}\text { Post- } \\
\text { neonatal }^{2}\end{array}$ & Infant $^{1}$ \\
\hline 1 (least deprived) & 1.6 & 0.6 & 2.2 & 1.8 & 0.8 & 2.5 & 2.0 & 1.3 & 3.3 & - & - & - & 1.7 & 0.8 & 2.4 \\
\hline 2 & 2.0 & 0.1 & 2.1 & 1.8 & 0.4 & 2.2 & 2.7 & 1.7 & 4.3 & 6.0 & 4.0 & 10.0 & 2.2 & 0.7 & 3.0 \\
\hline 3 & 2.4 & 0.9 & 3.3 & 2.2 & 1.1 & 3.3 & 2.8 & 1.5 & 4.2 & 4.8 & 2.4 & 7.3 & 2.6 & 1.2 & 3.8 \\
\hline 4 & 2.3 & 1.0 & 3.4 & 2.6 & 1.9 & 4.5 & 3.8 & 1.1 & 4.9 & 3.5 & 2.9 & 6.4 & 3.1 & 1.4 & 4.5 \\
\hline 5 (most deprived) & 3.3 & 1.3 & 4.6 & 3.2 & 2.0 & 5.2 & 4.3 & 1.1 & 5.4 & 5.7 & 1.3 & 6.9 & 4.0 & 1.3 & 5.4 \\
\hline All & 2.2 & 0.7 & 3.0 & 2.3 & 1.3 & 3.6 & 3.4 & 1.3 & 4.7 & 4.8 & 1.9 & 6.8 & 2.9 & 1.1 & 4.0 \\
\hline
\end{tabular}

1 Neonatal and infant mortality rates are given per 1,000 live births.

2 Postneonatal mortality rates are given per 1,000 live births surviving the neonatal period.

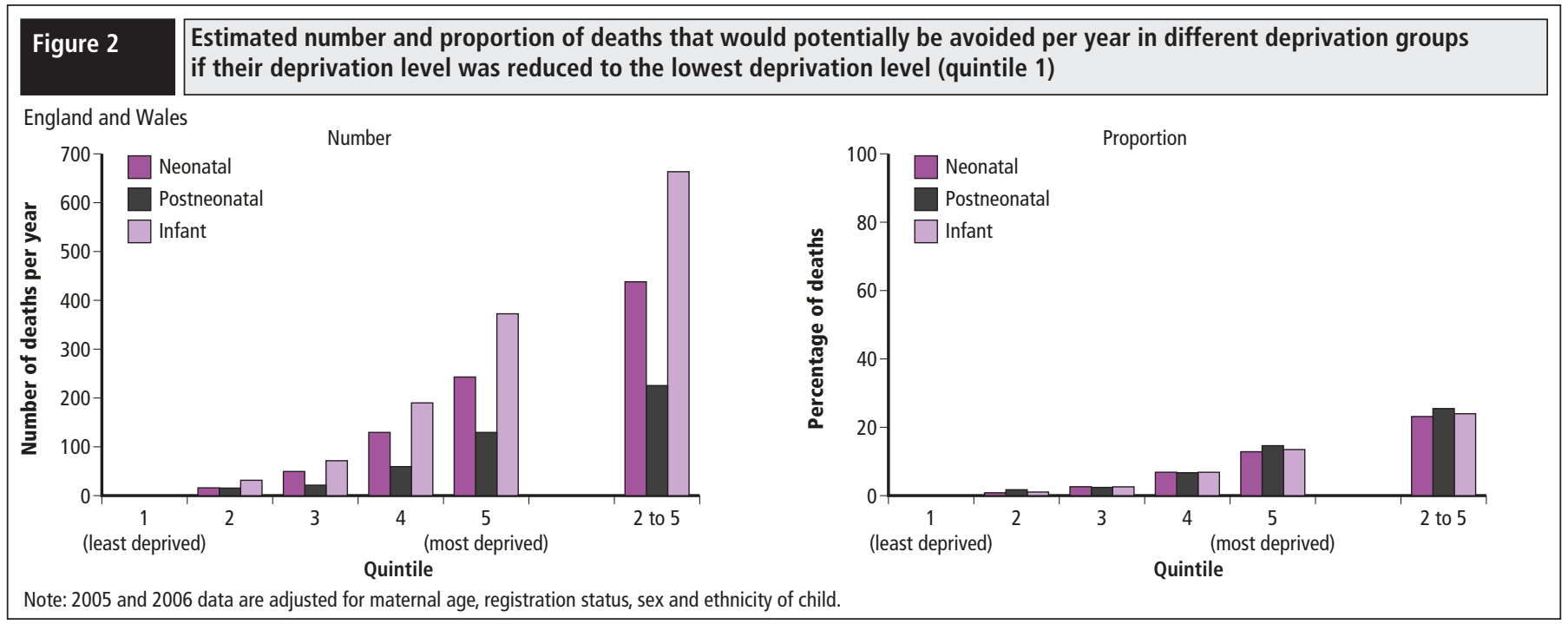

As might be expected, there was no association between sex of the baby and deprivation level $(\mathrm{P}>0.05)$. Preterm delivery, low birthweight and small-for-gestational-age ( $<5$ th centile, adjusted for gender) all showed marked increasing trends in prevalence with increasing levels of deprivation (Appendix Table A1).

\section{Association between deprivation/socio-economic status and infant mortality}

\section{Carstairs deprivation index}

There was a highly statistically significant independent association between deprivation and risk of infant mortality, similar in both neonatal and postneonatal periods, with a marked trend of increasing risk of infant mortality with increasing levels of deprivation (Tables 4 to 6). There was evidence of some confounding of this relationship by maternal age, registration status and sex and ethnicity of the baby, though the association remained after adjustment for these factors. For example, after adjustment, risk of overall infant mortality in the most deprived group was estimated to be around 1.6 times that in the least deprived group (OR (95 per cent CI): $1.57(1.41,1.75))$, having reduced from a crude OR of around two (Table 6). The number and proportion of excess deaths, which potentially would be avoided if deprivation levels reduced to the lowest level, rose with increasing levels of deprivation. Twenty-four per cent of all infant deaths, equivalent to around 666 deaths per year, would potentially be avoided if all mothers had the lowest deprivation level (Table 6 and Figure 2).

There was strong evidence of an interaction between deprivation and (separately) birthweight, gestation and small-for-gestational-age (Table 7). Among low birthweight babies, there was only a very weak, if any, association between deprivation and infant mortality risk. Among babies weighing 2,500 grams or more, however, there was a marked trend of increasing risk of infant mortality with increasing deprivation, strongest in the postneonatal period; ORs ( 95 per cent $\mathrm{CI}$ ) rising steadily to $1.35(1.09,1.67)$ and $1.83(1.44,2.32)$ for the most deprived compared to least deprived groups in the neonatal and postneonatal periods respectively (Table 7 and Figure 3). With regard to actual impact on infant mortality in the general population, however, in the neonatal period more deaths could potentially be avoided per year among low birthweight babies than babies

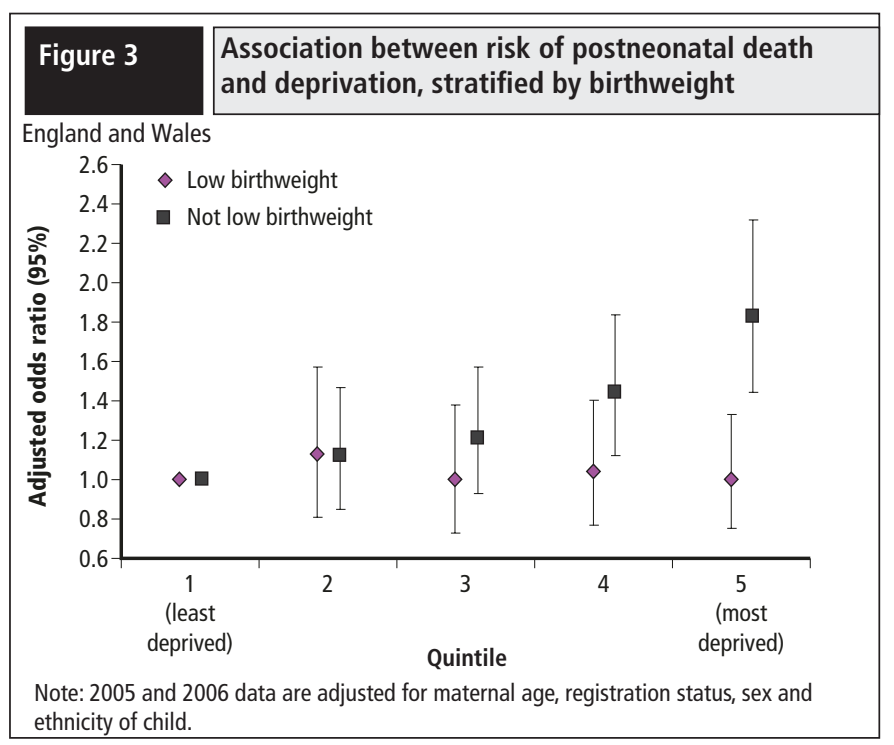




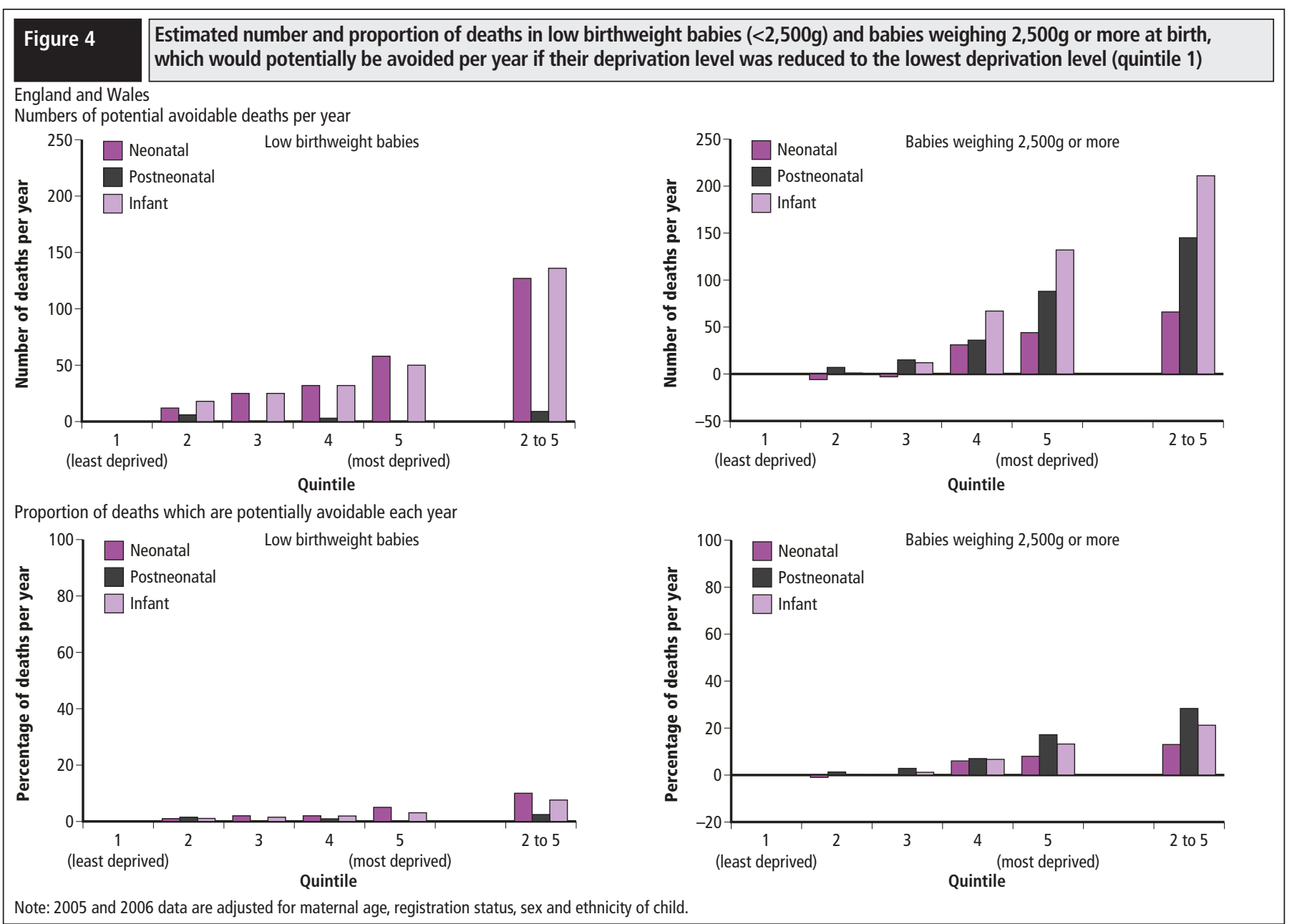

weighing 2,500 grams or more if the level of deprivation were reduced within each category to that of the least deprived group (127 deaths versus 66 deaths per year). In the postneonatal period, more deaths could potentially be avoided in this way among non-low birthweight babies (145 versus 9 deaths per year) (Table 7 and Figure 4).

With regard to the interaction between deprivation and gestation, in the neonatal period there was a steadily increasing trend in mortality risk with increasing deprivation among preterm babies (Table 7). For term babies, although odds ratios were raised in the two most deprived categories, there was no evidence of a difference in mortality risk among the first three deprivation groups. Conversely, in the postneonatal period, there was no consistent trend of mortality risk with deprivation among preterm babies (though the odds ratios were raised for all categories relative to the least deprived group), but there was a marked trend of increasing mortality risk with increasing levels of deprivation among babies who were not preterm. Figure 5 displays the numbers and proportions of deaths attributable to deprivation in preterm and term babies. If deprivation were reduced to the lowest level, 227 neonatal deaths could be avoided in the preterm group (representing 18 per cent of all deaths in this group), and 131 postneonatal deaths could be avoided in the term group ( 24 per cent of all deaths in this group).

Examining the interaction between deprivation and small-forgestational-age, the effect of deprivation was much stronger in non-smallfor-gestational-age than small-for-gestational-age babies in both neonatal and postneonatal periods (Table 7). Among small-for-gestational-age babies there was a shallow trend of increasing risk with increasing level of deprivation in the neonatal period, but in the postneonatal period there was no evidence of an effect of deprivation on risk of death. Among babies whose sex-specific weight for gestation was at the 5 th centile or above, there were marked trends of increasing odds ratios with increasing level of deprivation in both time periods (Table 7). With regard to potentially avoidable deaths, if deprivation levels reduced to the lowest level, 303 neonatal deaths and 220 postneonatal deaths in non-small-forgestational-age babies could be saved. These numbers represent 21 per cent and 30 per cent respectively of all deaths in these groups (Table 7).

\section{Socio-economic status}

Among the 10 per cent sample of births where the mother and father were both named on the birth certificate (inside marriage, or outside marriage registered by both parents), and hence where NS-SEC could be coded, there was a highly statistically significant independent association between NS-SEC and risk of infant mortality, similar in both neonatal and postneonatal periods, with a marked trend of increasing risk of infant mortality with decreasing socio-economic class (Tables 4 to 6). As with deprivation, there was evidence of some confounding of this relationship by maternal age, sex of baby, registration status and ethnicity of the baby, but the association remained after adjustment for these factors, though many of the odds ratios were no longer statistically significant. There was strong evidence of an interaction between NS-SEC and (separately) birthweight, gestation and smallness-for-gestational-age, with similar patterns of odds ratios to those observed for deprivation status. However due to small numbers, the results are not presented here.

Association between infant mortality and potential confounding factors/proximal risk factors (birthweight and gestation)

Confounding factors

As expected, all potential confounding factors under examination 


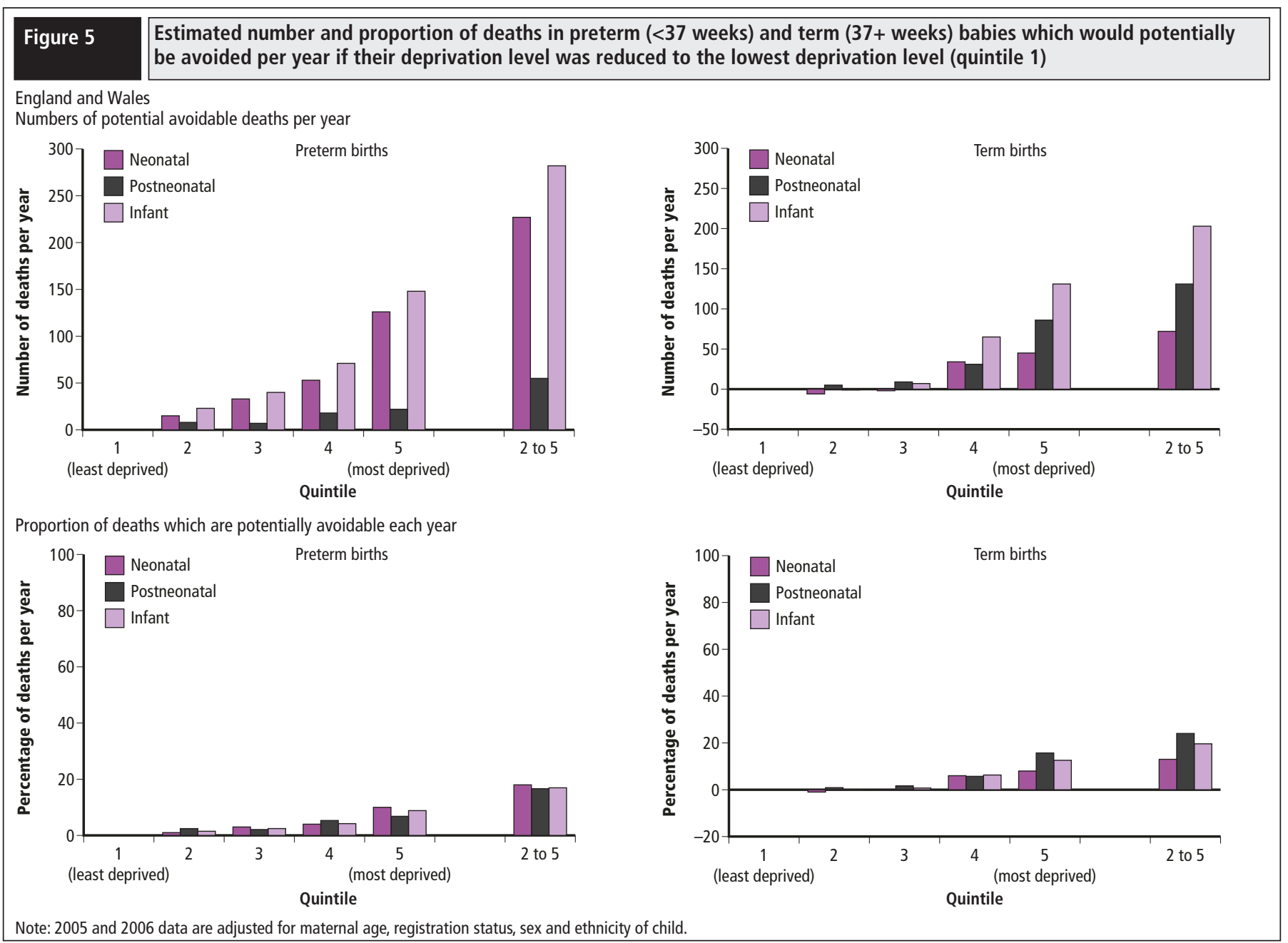

were strongly independently related to risk of infant mortality in both neonatal and postneonatal periods (Tables 4 to 6). Relative risks of mortality tended to be highest for babies where the mother was young (aged under 25) or older (aged 40 and over) (compared with mothers aged 25-29), where the parents were unmarried (particularly where the birth was registered by the mother alone or registered by both parents living at different addresses, compared with those where the parents were married), and where mothers were born outside the UK (compared with those born in the UK). Large increases in mortality odds ratios for babies described by their mother as being of non-White ethnic origin were also observed (relative to those described as White), particularly among those described as Asian or Black, and odds ratios for male babies were consistently high relative to females. None of these effects was substantially reduced in either the neonatal or the postneonatal group, after adjustment for maternal age, baby's sex, registration status, deprivation and ethnicity of the baby (as appropriate). Maternal country of birth could not be included in any models including ethnicity of the baby, due to the high correlation between these factors. However, with the exception of baby's sex, where estimates remained almost unchanged, when birthweight or gestation were additionally included in the models (Model 4 and 5) all odds ratios tended to reduce sharply, though the overall effects of registration status, maternal age and baby's ethnicity remained statistically significant independent predictors of mortality (all $\mathrm{P}<0.03$ ). Baby's sex was a highly significant independent risk factor for infant mortality, apparently unaffected by any other factor available in this analysis $(\mathrm{P}<0.005$ for neonatal, postneonatal and infant mortality).

\section{Registration status:}

In the neonatal period, for sole registrations, and joint registrations by parents living at different addresses, there was no apparent raised risk after additional adjustment for birthweight or gestation plus maternal age, deprivation, and sex and ethnicity of the baby. Babies whose parents lived at the same address, but were not married, had an apparent 14 per cent and 20 per cent raised risk compared with those born inside marriage after additionally controlling for these factors (ORs (95 per cent CI): $1.14(1.04,1.25)$ and $1.20(1.10,1.31)$ adjusted for birthweight and gestation respectively) (Table 4). This rather unexpected result may simply be a chance finding due to the large number of statistical estimations involved in the analyses. Conversely, in the postneonatal period there was no apparent increase in risk after additional adjustment for birthweight or gestation among joint registrations with the same address relative to births inside marriage. However, sole registrations had 67 per cent and 82 per cent increased risks even after further adjustment for these more proximal risk factors (ORs (95 per cent CI): $1.67(1.40,1.98)$ and $1.82(1.52,2.15)$ adjusted additionally for birthweight and gestation respectively). Calculations of excess deaths showed that after full adjustment around 5 per cent of all postneonatal deaths were independently associated with sole registration (Table 5). Babies whose parents did not live at the same address also had raised risks of postneonatal mortality (ORs (95 per cent CI): $1.32(1.11,1.57)$ and $1.40(1.17,1.66)$ after additional adjustment for birthweight and gestation respectively) (Table 5).

\section{Maternal age:}

In the neonatal period, odds ratios for very young $(<20$ years) and older ( 40 and over) mothers were raised relative to mothers aged 25-29 after additional adjustment for birthweight, but not statistically significantly so (except for a borderline result for mothers aged 40 and over) (Table 4). In the postneonatal period, odds ratios were significantly raised for both mothers under the age of 25 (ORs (95 per cent CI) $1.38(1.14,1.67)$ and 
$1.36(1.18,1.57)$ (maternal age $<20)$, and $1.41(1.16,1.71)$ and $1.39(1.21,1.61)$ (maternal age 20-24)), and for those aged 35 and over (ORs (95 per cent CI) $1.23(1.04,1.45)$ and $1.22(1.04,1.44)$ (maternal age 35-39), after adjustment for birthweight or gestation respectively) (Table 5). Over 12 per cent of postneonatal deaths could be independently attributed to maternal age above or below age 25-29 (Table 5).

\section{Baby's sex:}

Inclusion of other factors in the model made very little difference to the effect of sex. In both neonatal and postneonatal periods relative risk of mortality was consistently and independently raised among boys, risks being around 15-30 per cent higher than those of girls (ORs ( 95 per cent $\mathrm{CI}$ ): $1.33(1.25,1.43)$ and $1.12(1.04,1.20)$ in the neonatal period, and $1.28(1.16,1.43)$ and $1.16(1.06,1.30)$ in the postneonatal period, after adjustment for all other risk factors, and birthweight and gestation respectively) (Tables 4 and 5). In the fully adjusted model including birthweight, male sex accounted for 13 per cent of all infant deaths (Table 6).

\section{Ethnicity of the baby:}

Babies of non-White ethnic origin (as described by the mother) had raised odds ratios in both neonatal and postneonatal periods, though this increase was restricted to babies described as Asian in the latter period. After adjustment for all other potential confounders and birthweight, ORs ( 95 per cent CIs) in the neonatal period were up to 40 per cent higher compared with babies described as White $(1.13(1.00,1.27), 1.42(1.24$, $1.64)$ and $1.11(0.98,1.25)$ in Asian, Black and Other non-White babies respectively). Adjusted additionally for gestation rather than birthweight, the estimates were even higher, at $1.63(1.44,1.85), 1.60(1.40,1.83)$ and $1.24(1.10,1.40)$ (Table 4$)$. In the postneonatal period, the corresponding odds ratios for babies described as Asian were $1.49(1.26,1.77)$ and 1.86 $(1.57,2.20)$ respectively. Around 5 per cent of all infant deaths in the population could be attributed to non-white ethnicity, independent of birthweight (Table 6).

Proximal risk factors (further along the causal pathway than deprivation) - gestation and birthweight

Almost 60 per cent of all infant deaths could be attributed to either low birthweight or preterm delivery (Table 6; 'Excess deaths \%' column; Model 3).

\section{Birthweight:}

Birthweight was a major risk factor for infant mortality - having a greater effect than any other factor except for gestation (there is considerable overlap between the two factors) (Tables 4 to 6). Maternal age- and sex-adjusted odds ratios (relative to babies weighing 2,500 to 4,499 grams) rose to around 230 for neonatal mortality and over 45 for postneonatal mortality in extremely low birthweight infants (Tables 4 and 5 respectively). There was, however, a highly statistically significant interaction between the effects of birthweight (low birthweight) and Carstairs deprivation on infant mortality, stronger than that between gestation and deprivation, and present in all time periods (all $\mathrm{P} \leq 0.01$ ) (Table 8). The effect of low birthweight on infant mortality decreased markedly with increasing levels of deprivation, adjusted (for maternal age, registration status and baby's sex and ethnicity) odds ratios decreasing by a third between the highest (least deprived) and lowest (most deprived) groups from $28.73(24.00,34.39)$ to $19.46(17.65,21.45)$. The effect modification was most marked in the postneonatal period, where adjusted relative risks reduced by almost half from the least to most deprived groups, but was also substantial in the neonatal period, with a 15 to 30 per cent decline between the effect of low birthweight in the top and bottom deprivation categories. Excess neonatal deaths attributed to low birthweight per year varied between 460 for the most deprived and 121 for the least deprived, and equivalent figures for postneonatal deaths were 121 for the most deprived and 32 for the least deprived (Table 8).

\section{Gestational age:}

The effect of gestation on risk of infant mortality was higher than that of any other factor by an order of magnitude (Tables 4 to 6 ), with maternal age- and sex-adjusted odds ratios (relative to term babies) of up to around 650 for neonatal mortality and over 90 for postneonatal mortality in extremely preterm babies (Tables 4 and 5 respectively).

Again, there was a statistically significant interaction between the effects of gestation (preterm delivery) and Carstairs deprivation index on infant mortality $(\mathrm{P}=0.01)$ (Table 8$)$. This was driven by a strong interaction between these factors in the postneonatal period $(\mathrm{P}=0.03)$ where there was a 30 per cent decline in adjusted (for maternal age, registration status and baby's sex and ethnicity) odds ratios between the least deprived $(10.13(7.28,14.09))$ and most deprived $(7.40(6.27,8.74))$ groups. There was a large number of postneonatal deaths attributed to preterm delivery in the most deprived group (104) compared to that in the least deprived group (27), although the proportions of these excess deaths were similar at around 30 per cent for each group. There was no evidence of an interaction between gestation and deprivation in the neonatal period $(\mathrm{P}=0.14)$ (Table 8).

\section{Small-for-gestational-age:}

Live-born babies whose weight was below the 5 th centile of the distribution expected for their sex and gestation had more than three times the risk of dying in the first year of life as those whose weight was above this level (Tables 4 to 6 ). Though the odds ratios in all age periods were high, their magnitude in relation to those of absolute birthweight and gestation indicate that the latter are the more critical factors in terms of predicting risk of infant death. As with gestation and birthweight, there was an interaction between the effects of small-for-gestational-age and Carstairs deprivation on infant mortality, most marked in the postneonatal period where the effect of being small-for-gestational-age in the least deprived group was almost double that in the most deprived group (OR (95 per cent CI): $5.40(3.49,8.36)$ versus $2.88(2.35,3.53)$ ). The excess number of postneonatal deaths attributed to small-for-gestationalage ranged between 11 for the least deprived group and 42 for the most deprived group (Table 8).

\section{Discussion}

Inequalities in infant mortality in England and Wales in 2005 and 2006 by deprivation, and socio-economic and biological factors was investigated in this analysis. Multivariate analysis was undertaken to obtain information on the independent contributions of individual factors to the risk of death. The approach was to use both the strength of association between various factors and risk of death, measured as adjusted odds ratios, and the theoretical impact of these factors on the number and proportion of 'excess' deaths in the population that could potentially be saved, or avoided, if the factor was not present.

The emphasis of this work was on socio-economic inequalities in infant mortality. The national health inequalities PSA target was set in 2001 and was updated in 2004 . The target is to 'Reduce health inequalities by 10 per cent by 2010 as measured by infant mortality and life expectancy at birth'. 6 More specifically this target is underpinned by an objective to reduce by at least 10 per cent the gap in mortality between the routine and manual group and the population as a whole by 2010 . A second objective is, also by 2010 , to reduce by at least 10 per cent the gap in life expectancy at birth between the fifth of areas with the worst health and deprivation indicators (the Spearhead Group) and the population as a whole.

This analysis was limited by the number of births coded to NS-SEC (only 10 per cent are coded), and hence the main analyses were on the area level of deprivation, using the Carstairs index of deprivation. 
Despite its limitations, this indicator performed well as a marker for socio-economic status and, since it was available for all births and deaths, it enabled multivariate analyses to be conducted with good statistical power.

The findings are consistent with those of other studies based on England and Wales data that have found variation in infant mortality by birthweight, gestation, mother's age, registration status, sex and ethnicity of the child. ${ }^{4,10,11}$ The very strong links between risk of neonatal death and both low birthweight and preterm delivery were confirmed. After controlling for maternal age and sex of child, over two-thirds of all neonatal deaths could be attributed to these factors in 2005 and 2006. The multivariate approach also confirmed independent effects of registration status, ethnicity of child, and male sex, after allowing for birthweight or gestational age and other confounding factors.

Low birthweight and preterm delivery are the main proximal risk factors for death under one year, especially under one month, and both factors are highly associated with socio-economic status and deprivation. The finding that approximately one quarter of all infant deaths could be avoided if all mothers had the lowest deprivation level is at least partly mediated through low birthweight and/or prematurity. When the impact of deprivation on risk of death over and above that of low birthweight and preterm delivery was examined, perhaps not surprisingly, evidence of interaction was found. Stratified analyses, for example within term babies only, revealed residual associations between deprivation and risk of death with a consistent pattern of stronger associations for babies who were not low birthweight, and term, than for babies who were low birthweight or preterm. These associations were much stronger for postneonatal than for neonatal death, an observation reported in a previous study by Leon. ${ }^{18}$ An estimated 28 per cent of postneonatal deaths in babies weighing 2,500 grams or more, equivalent to 145 postneonatal deaths per year in this group, could be explained by deprivation levels being above the lowest (least deprived) level. Similarly, 24 per cent of postneonatal deaths in term babies, equivalent to 131 postneonatal deaths among term babies per year, were explained by deprivation levels above the least deprived category. These deaths are potentially avoidable if the deprivation gap is eliminated for all mothers.

There was no information from birth, death or NN4B records on more specific, and possibly more proximal, environmental, social, economic or behavioural exposures related to deprivation, or on access to and uptake of health or social care, which may explain these findings. Smoking, obesity, poor nutrition and inadequate antenatal care are likely to be more prevalent in groups of mothers with higher levels of deprivation, and may contribute to the effects reported here. Further work to investigate the explanatory causal pathways between deprivation and infant mortality, perhaps for specific causes of death, is required. This will inform interventions to reduce the inequalities in infant death described in this paper and thus contribute towards reducing the infant mortality gap identified in the PSA target. ${ }^{6}$

\section{Key findings}

- Among all singleton live births in England and Wales, 2005-06, as levels of deprivation increased, mothers tended to be younger, less likely to be married or living with the father, and more likely to be non-UK-born

- Babies who were Asian, Black or of other non-white ethnicity tended to have higher levels of deprivation

- Preterm birth, low birthweight and small-for-gestational-age increased in prevalence with increasing levels of deprivation

- Deprivation, births outside marriage, non-white ethnicity of infant, maternal age under the age of 20 and male sex were all independently associated with an increased risk of infant mortality

- Lower birthweight, earlier gestation and small-for-gestational-age were strongly associated with infant mortality, with the effect of birthweight and gestation most marked in the neonatal period

- The effect of deprivation on death in the first year of life was partly confounded by maternal age, registration status/marital type and ethnicity of baby, but a trend of increasing risk of death with increasing deprivation persisted after adjustment. One quarter of all deaths under one year would potentially be avoided if all births were to women with the lowest level of deprivation

- Trends of increasing mortality risk with increasing deprivation tended to be strongest in the postneonatal period

- Statistically significant interactions were found between deprivation and low birthweight, preterm and small-forgestational-age. There was a stronger association between deprivation and infant mortality among babies who were not low birthweight, and among non-small-for-gestational-age babies. With regard to gestation, the strongest effect of deprivation was observed among preterm births in the neonatal period, and among term births in the postneonatal period

- Around 28 per cent of postneonatal deaths (45 per year) among non-low birthweight babies, and 24 per cent of postneonatal deaths (131 per year) among babies born at term, would potentially be avoided if all levels of deprivation were reduced to that of the least deprived group

- The National Statistics Socio-economic Classification showed similar associations with infant mortality to deprivation, but small numbers prohibited the calculation of fully adjusted models using this factor 


\section{References}

1. Rush R W, Keirse M J, Howat P et al (1976) 'Contribution of preterm delivery to perinatal mortality', British Medical Journal 2, 965-68.

2. McCormick M C (1985) 'The contribution of low birth weight to infant mortality and childhood morbidity', New England Journal of Medicine 312, 82-90.

3. Botting B, Davies I and Macfarlane A (1987) 'Recent trends in the incidence of multiple births and associated mortality', Archives of Disease in Childhood 62(9), 941-50.

4. Moser K, Macfarlane A, Chow Y H et al (2007) 'Introducing new data on gestation-specific infant mortality among babies born in 2005 in England and Wales', Health Statistics Quarterly 35,13-27. Available on the Office for National Statistics website at: www.statistics.gov.uk/statbase/Product.asp?vlnk $=6725$

5. Moser K (2007) 'Report: Infant and perinatal mortality in England and Wales by social and biological factors, 2007', Health Statistics Quarterly 40, 61-65. Available on the Office for National Statistics website at: www.statistics.gov.uk/statbase/Product.asp?vlnk $=6725$

6. Department of Health (2003) Tackling health inequalities: A Programme for Action, Series Cm 6374, Department of Health: London.

7. Guildea Z E, Fone D L, Dunstan F D et al (2001) 'Social deprivation and the causes of stillbirth and infant mortality', Archives of Disease in Childhood 84(4), 307-10.

8. Joyce R, Webb R, Peacock J L and Stirland H (2000) 'Which is the best deprivation predictor of foetal and infant mortality rates?', Public Health 114(1), 21-24.

9. Dummer T J B and Parker L (2005) 'Changing socioeconomic inequality in infant mortality in Cumbria', Archives of Disease in Childhood 90(2), 157-62.

10. Maher J and Macfarlane A (2004) 'Inequalities in infant mortality: trends by social class, registration status, mother's age and birthweight,
England and Wales, 1976-2000', Health Statistics Quarterly 24, 14-22. Available on the Office for National Statistics website at: www.statistics.gov.uk/statbase/Product.asp?vlnk $=6725$

11. Dattani N, Cooper N, Rooney C et al (2000) 'Analysis of risk factors for neonatal mortality in England and Wales, 1993-97: based on singleton babies weighing 2,500 - 5,499 grams', Health Statistics Quarterly 08, 29-35. Available on the Office for National Statistics website at: www.statistics.gov.uk/statbase/Product.asp?vlnk $=6725$

12. Hilder L, Moser K, Dattani N and Macfarlane A (2007) 'Pilot linkage of NHS Numbers for Babies data with birth registrations', Health Statistics Quarterly 33, 25-33. Available on the Office for National Statistics website at: www.statistics.gov.uk/statbase/Product.asp?vlnk $=6725$

13. Office for National Statistics (2008) Mortality statistics: Childhood, infant and perinatal, 2006, Series DH3 no. 39, The Stationery Office: London.

14. Office for National Statistics (2002) The National Statistics SocioEconomic Classification User Manual: Version no. 1, The Stationery Office: London.

15. Morgan O and Baker A (2006) 'Measuring deprivation in England and Wales using 2001 Carstairs scores', Health Statistics Quarterly 31, 28-33. Available on the Office for National Statistics website at: www.statistics.gov.uk/statbase/Product.asp?vlnk $=6725$

16. Dattani N and Rowan S (2002) 'Causes of neonatal deaths and stillbirths: a new hierarchical classification in ICD-10', Health Statistics Quarterly 15, 16-22. Available on the Office for National Statistics website at:

www.statistics.gov.uk/statbase/Product.asp?vlnk=6725

17. Clayton D and Hills M (1993) Statistical Methods in Epidemiology, Oxford University Press: Oxford.

18. Leon D A (1991) 'Influence of birth weight on differences in infant mortality by social class and legitimacy', British Medical Journal 303(6808), 964-67. 


\begin{tabular}{|c|c|c|c|c|c|c|}
\hline & \multicolumn{6}{|c|}{ Neonatal mortality } \\
\hline & Unadjusted & Model 1 & Model 2 & Model 3 & Model 4 & Model 5 \\
\hline & & Adjusted for age and sex ${ }^{1}$ & $\begin{array}{l}\text { Model } 1+\text { adjusted } \\
\text { for deprivation and } \\
\text { registration status } 5^{1,2}\end{array}$ & $\begin{array}{l}\text { Model } 2+\text { adjusted for } \\
\text { ethnicity of baby }\end{array}$ & $\begin{array}{l}\text { Model } 3+\text { adjusted for } \\
\text { interaction between } \\
\text { birthweight and } \\
\text { deprivation }\end{array}$ & $\begin{array}{c}\text { Model } 3+\text { adjusted } \\
\text { for interaction } \\
\text { between gestation and } \\
\text { deprivation }\end{array}$ \\
\hline & OR $(95 \% \mathrm{Cl})$ & OR $(95 \% \mathrm{Cl})$ & OR $(95 \% \mathrm{Cl})$ & OR $(95 \% \mathrm{Cl})$ & OR $(95 \% \mathrm{Cl})$ & OR $(95 \% \mathrm{Cl})$ \\
\hline
\end{tabular}

$\begin{array}{ll}\begin{array}{l}\text { Deprivation and socio-economic status } \\ \text { Carstairs deprivation index } \\ 1 \text { (least deprived) }\end{array} & 1.00 \\ 2 & 1.14(1.00,1.30)^{*} \\ 3 & 1.29(1.14,1.47)^{* * *} \\ 4 & 1.62(1.43,1.82)^{* * *} \\ 5 \text { (most deprived) } & 2.00(1.79,2.24)\end{array}$

\begin{tabular}{ll}
1.00 & \multicolumn{1}{c}{1.00} \\
$1.13(0.99,1.30)$ & $1.12(0.98,1.28)$ \\
$1.27(1.12,1.44)^{* * *}$ & $1.25(1.10,1.42)^{* *}$ \\
$1.57(1.39,1.77)^{* * *}$ & $1.53(1.36,1.72)^{* * *}$ \\
$1.94(1.73,2.17)^{* * *}$ & $1.90(1.69,2.13)^{* * *}$
\end{tabular}

1.00
$1.07(0.92,1.23)$
$1.19(1.04,1.37)^{*}$
$1.41(1.24,1.61)^{* * *}$
$1.54(1.36,1.75)^{* * *}$

-
Pooled odds ratios
not calculated due to
iteraction. See Table 8

- $\quad$ Model 3

$1.54(1.36,1.75)^{* * *}$ $\begin{array}{lcc}\text { Pooled odds ratios } & 2.61 \\ \text { to } & \text { not calculated due to } & 6.85\end{array}$
1.00

\begin{tabular}{llllc} 
NS-SEC & \multicolumn{1}{c}{} & \multicolumn{1}{c}{1.00} & 1.00 & 1.00 \\
Higher and professional & 1.00 & $1.05(0.75,1.47)$ & $1.03(0.74,1.44)$ & $1.00(0.70,1.43)$ \\
Intermediate & $1.04(0.75,1.45)$ & $1.58(1.22,2.06)^{*}$ & $1.53(1.17,2.00)^{*}$ & $1.33(1.00,1.77)$ \\
$\begin{array}{l}\text { Routine and manual } \\
\text { Other (unemployed/ }\end{array}$ & $1.54(1.20,1.98)^{*}$ & $2.19(1.47,3.27)^{* * *}$ & $2.18(1.46,3.26)^{* * *}$ & $1.67(1.08,2.58)^{*}$ \\
students/ns) & $2.17(1.47,3.18)^{* * *}$ & 2.19
\end{tabular}

Other (unemploye
students/ns)

$2.17(1.47,3.18)^{* * *}$

$2.19(1.47,3.27)^{\star * *} \quad 2.18(1.46,3.26)^{* * *}$
23.16
Pooled odds ratios not calculated due to interaction with
birthweight

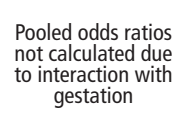

Model 3

$11 . \overline{0}$

4.12

15.18

\section{Potential confounding factors}

Registration type/Marital status

Married

Sole registration ${ }^{4}$

Joint registration/same

1.00

address

$1.34(1.18,1.51)^{* * *}$

$1.25(1.16,1.34)^{* * *}$

$1.50(1.35,1.66)^{* * *}$

1.00

$1.24(1.10,1.41)^{* *} \quad 1.14(1.00 .1 .29)^{*}$

$1.20(1.11,1.29)^{* * *} \quad 1.18(1.09,1.28)^{* * *}$

$1.39(1.24,1.55)^{* * *} \quad 1.28(1.14,1.43)^{* * *}$

different address ${ }^{5}$

$1.28(1.14,1.45)^{* * *}$
$1.05(0.96,1.15)$
$\quad 1.00$
$0.81(0.74,0.89)^{* * *}$
$0.88(0.79,0.97)$
$1.20(1.01,1.41)$

$1.28(1.14,1.44)^{* * *}$ $1.05(0.95,1.15)$ 1.00

$1.10(0.97,1.25)$

$0.95(0.86,1.05)$

1.00

$0.81(0.74,0.89)^{* * *} \quad 0.89(0.81,0.97)^{*}$

$0.88(0.79,0.97)^{*}$

$0.97(0.88,1.08)$

$1.31(1.11,1.54)^{* *}$
$1.26(1.10,1.45)^{*}$

$1.36(1.24,1.48)^{* * *}$

$1.43(1.27,1.62)^{* * *}$
$1.16(1.01,1.32)^{*}$ $0.96(0.89,1.06)$ 1.00

$0.92(0.84,1.02)$

$1.03(0.92,1.15)$

$1.41(1.18,1.68)^{* * *}$
1.00
$0.86(0.75,1.00)^{*}$
$1.14(1.04,1.25)^{*}$

$1.05(0.93,1.19)$

$1.10(0.95,1.26)$ $0.94(0.85,1.04)$ 1.00

$0.94(0.85,1.03)$

$0.98(0.87,1.10)$

$1.21(1.00,1.45)^{*}$

\begin{tabular}{crrr}
1.00 & \multicolumn{3}{c}{ Model 3 Model 4 Model 5} \\
$0.93(0.81,1.07)$ & 1.69 & -1.33 & -0.62 \\
$1.20(1.10,1.31)^{* * *}$ & 7.99 & 3.71 & 5.03 \\
$1.13(1.00,1.28)$ & 3.53 & 0.56 & 1.35 \\
& 13.21 & 2.93 & 5.76 \\
& Model 3 Model 4 Model 5 \\
$1.13(0.99,1.30)$ & 1.28 & 0.85 & 1.07 \\
$0.98(0.88,1.08)$ & -0.87 & -1.34 & -0.43 \\
1.00 & - & - & - \\
$0.90(0.81,0.99)^{*}$ & -2.09 & -1.54 & -2.67 \\
$0.95(0.85,1.06)$ & 0.43 & -0.30 & -0.77 \\
$1.17(0.98,1.41)$ & 1.24 & 0.74 & 0.42 \\
& -0.01 & -1.59 & -2.38
\end{tabular}

Unable to be calculated Unable to be calculated Unable to be calculated Model 2

due to high correlation due to high correlation 4.43

due to high correlation due to high correlation
of country of birth of country of birth

\& ethnicity
\& ethnicity

$1.22(1.14,1.30)^{* * *}$

$\begin{array}{cc}1.00 & 1.00 \\ 1.22(1.14,1.30)^{* * *} & 1.22(1.14,1.30)^{* * *}\end{array}$

1.00

$1.33(1.25,1.43)^{* * *}$

1.00

$1.13(1.00,1.27)$

$1.42(1.24,1.64)^{* * *}$

$1.11(0.98,1.25)$

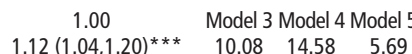

$1.00 \quad$ Model 2 Model 4 Model 5

$1.77(1.60,1.97)^{* * *} \quad 1.83(1.62,2.06)^{* * *}$ $\begin{array}{ll}1.99(1.76,2.26)^{* * *} & 1.74(1.52,1.99)^{* * *} \\ 1.34(1.19,1.50)^{* * *} & 1.28(1.14,1.44)^{* * *}\end{array}$

Equivalent to Model 2

$1.99(1.75,2.26)^{* * *}$

$1.34(1.20,1.50)^{* * *}$
$1.63(1.44,1.85)^{* * *}$

$1.60(1.40,1.83)^{* * *}$

$1.24(1.10,1.40)^{* * *}$
Black Caribbean

Other

Factors on causal pathway

Birthweight (grams)

$<1,500$
$1,500-2,499$
$2,500-4,499$
$232.46(215,251.11)^{* * *}$ $8.70(7.81,9.68)^{*}$ 1.00
$0.99(0.63,1.56)$

$2,500-4,499$
4,500 and over
$231.70(214.46,250.33)^{* * *}$ $8.71(7.82,9.70)^{* * *}$
1.00 $0.96(0.61,1.52)$ $\begin{array}{ccc}\begin{array}{c}\text { Interaction between } \\ \text { birthweight and } \\ \text { deprivation. See Table } 7\end{array} & \begin{array}{c}\text { Interaction between } \\ \text { birthweight and } \\ \text { deprivation. See Table } 7\end{array} & \begin{array}{c}\text { Interaction between } \\ \text { birthweight and } \\ \text { deprivation. See Table }\end{array}\end{array}$ eprivation. See Table 7 deprivation. See Table 7

$\begin{array}{cr} & \text { Model } \\ & 56.94 \\ \text { Interaction between } & 12.15 \\ \text { birthweight and } & - \\ \text { deprivation. See Table } 7 & -\end{array}$ deprivation. See Table $7 \quad-0$ 69.06 Model 1 50.03

Gestation (weeks)

$21-27$

$28-31$

$32-36$

$37-41$
42 and over

$654.82(602.00,712.27)^{\star * *} \quad 649.46(596.98,706.56)^{* * *}$

$43.24(38.15,49.00)^{* * *} \quad 42.74(37.71,48.33)^{* * *}$ $7.20(6.42,8.07)^{* * *}$

1.00

$7.14(6.47,7.99)^{* * *}$

1.00

$1.01(0.77,1.34)$

\begin{tabular}{lll} 
Interaction between Interaction between Interaction between Interaction between & 8.91 \\
\hline
\end{tabular}

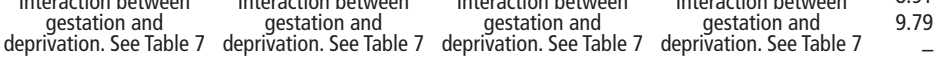

0.01

68.74

Model 1

Small for gestational age

$\mathrm{SGA}(<5 \%)$

$3.26(2.96,3.59)^{* * *}$

$3.19(2.89,3.51)^{* * *} \quad$ Interaction between

Interaction between

Interaction between

9.83

${ }^{*} p<0.05 \quad{ }^{* *} p<0.005 \quad{ }^{* * *} p<0.001$

1 Adjusted for covariate only where it is not the main explanatory variable in model.

2 Carstairs deprivation not adjusted for where NS-SEC is main explanatory variable.

3 Proportion of all deaths in population which potentially would be avoided if risk was same as that in baseline group.

4 Birth takes place outside marriage, only mother registers the birth.

5 Birth takes place outside marriage, both mother and father register the birth. 


\begin{tabular}{|c|c|c|c|c|c|c|c|}
\hline \multirow{4}{*}{ 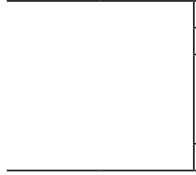 } & \multicolumn{6}{|c|}{ Postneonatal mortality } & \multirow{4}{*}{ Excess deaths $\%^{3}$} \\
\hline & Unadjusted & Model 1 & Model 2 & Model 3 & Model 4 & Model 5 & \\
\hline & & Adjusted for age and sex ${ }^{1}$ & $\begin{array}{l}\text { Model } 1+\text { adjusted } \\
\text { for deprivation and } \\
\text { registration status } \text { s.,2 }^{1,2}\end{array}$ & $\begin{array}{c}\text { Model } 2+\text { adjusted for } \\
\text { ethnicity of baby }\end{array}$ & $\begin{array}{l}\text { Model } 3+\text { adjusted for } \\
\text { interaction between } \\
\text { birthweight and } \\
\text { deprivation }\end{array}$ & $\begin{array}{c}\text { Model } 3+\text { adjusted } \\
\text { for interaction } \\
\text { between gestation and } \\
\text { deprivation }\end{array}$ & \\
\hline & OR $(95 \% \mathrm{Cl})$ & OR $(95 \% \mathrm{Cl})$ & OR $(95 \% \mathrm{Cl})$ & OR $(95 \% \mathrm{Cl})$ & OR $(95 \% \mathrm{Cl})$ & OR $(95 \% \mathrm{Cl})$ & \\
\hline
\end{tabular}

Deprivation and socio-economic status

Carstairs deprivation index

$\begin{array}{ll}2 & 1.18(0.97,1.44) \\ 3 & 1.32(1.09,1.60)^{* *} \\ 4 & 1.71(1.43,2.04)^{* * *} \\ 5 \text { (most deprived) } & 2.21(1.88,2.61)^{* * *}\end{array}$

$2.21(1.88,2.61)^{* * *}$

1.00
$1.15(0.94,1.40)$
$1.25(1.03,1.50)^{*}$
$1.55(1.30,1.86)^{* * *}$

1.00

$1.13(0.93,1.38)$

1.00

$1.55(1.30,1.86)^{* * *} \quad 1.49(1.24,1.78)^{* * *} \quad 1.40(1.16,1.70)^{* *}$

$1.97(1.66,2.34)^{* * *} \quad 1.86(1.57,2.20)^{* * *}$
$1.22(1.00,1.47)^{*} \quad 1.18(0.97,1.45)$

$\begin{array}{ccc} & & \text { Model } 3 \\ \text { Pooled odds ratios } & \text { Pooled odds ratios } & 1.73 \\ \text { not calculated due to } & \text { not calculated due to } & 2.41 \\ \text { interaction. See Table 8 } & \text { interaction. See Table } 8 & 6.72 \\ & & 14.62 \\ & 25.48\end{array}$

1.00

1. $59(0.96,2.62)$

$1.41(0.90,2.21)$

$1.96(1.02,3.78)^{*}$

$\begin{array}{cc}1.00 & 1.00 \\ 1.61(0.98,2.66) & 1.59(0.94,2.67) \\ 1.44(0.91,2.27) & 1.39(0.86,2.24) \\ 2.00(1.04,3.87)^{*} & 1.82(0.91,3.65)\end{array}$

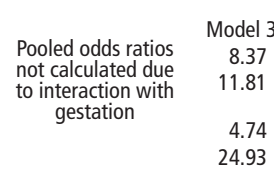

24.93

\section{Potential confounding factors}

Registration type/Marital status

$\begin{array}{lc}\begin{array}{l}\text { Married } \\ \text { Sole registration }\end{array} & 1.00 \\ \begin{array}{l}\text { Joint registration/ } \\ \text { same address }\end{array} & 2.38(2.06,2.74)^{* * *} \\ \begin{array}{l}\text { Joint registration/ } \\ \text { different address }\end{array} & 1.13(1.01,1.27)^{*} \\ & 1.74(1.51,2.02)^{* * *} \\ \text { Maternal age (years) } & \\ <20 & 1.79(1.52,2.13)^{* * *} \\ 20-24 & 1.53(1.34,1.74)^{* * *} \\ 25-29 & 1.00 \\ 30-34 & 0.82(0.71,0.94)^{*} \\ 35-39 & 1.02(0.87,1.19) \\ 40 \text { and over } & 1.04(0.79,1.37)\end{array}$

1.00

$1.96(1.68,2.29)^{* * *}$

$1.00(0.89,1.13)$

$1.42(1.21,1.67)^{* * *}$

$1.79(1.52,2.13)^{* * *}$

$1.53(1.34,1.74)^{* *}$

$$
1.00
$$

$0.82(0.71,0.94)^{*}$

$1.02(0.87,1.19)$

$1.04(0.79,1.37)$
1.00

$1.82(1.56,212)^{* * *} \quad 2.07(1.75,2.46$

$1.00(0.89,1.13)$

$1.34(1.14,1.57)^{* * *}$

$1.38(1.16,1.66)^{* * *}$

$1.35(1.18,1.54)^{* *}$

1.00

$0.89(0.77,1.03)$

$1.13(0.97,1.32)$

$1.06(0.80,1.41)$

$2.07(1.75,2.46)^{* * *}$

$1.20(1.05,1.37)^{*}$

$1.59(1.34,1.89)^{* * *}$

1.00

$1.67(1.40,1.98)^{* * *}$

$1.82(1.52,2.15)^{* * *}$

Model 3 Model 4 Model 5

$1.09(0.95,1.25)$

$1.14(1.00,1.30)$

$\begin{array}{lll}4.34 & 2.15 & 3.20\end{array}$

$1.32(1.11,1.57)^{*}$

$1.40(1.17,1.66)^{* * *}$

$\begin{array}{lll}4.81 & 3.14 & 3.70\end{array}$

$\begin{array}{lrr}16.20 & 10.77 \quad 13.05\end{array}$

Model 3 Model 4 Model 5

$1.40(1.16,1.70)^{* * *}$

$1.38(1.14,1.67)^{* *}$

$1.41(1.16,1.71)^{* * *}$

$\begin{array}{lll}3.22 & 3.10 & 3.28\end{array}$

$1.36(1.18,1.57)^{\star}$

$0.96(0.83,1.11)$

$1.27(1.08,1.50)^{* *}$

$1.36(1.18,1.57)$

$0.97(0.83,1.12)$

$1.23(1.04,1.45)^{*}$

$1.39(1.21,1.61)^{*}$

$0.95(0.82,1.11)$

$1.22(1.04,1.44)^{*}$

$1.03(0.76,1.40)$

$1.01(0.74,1.37)$

$\begin{array}{rrr}-0.88 & -0.65 & -1.11\end{array}$

$\begin{array}{rrr}-0.88 & -0.65 & -1.11 \\ 3.15 & 2.77 & 2.67\end{array}$

$\begin{array}{lll}0.29 & 0.09 & 0.03\end{array}$

$\begin{array}{lll}12.78 & 12.32 & 12.29\end{array}$

Maternal country of birth

UK

1.00
$1.09(0.97,1.22)$

1.00

1.00

$1.04(0.92,1.18)$

Unable to be calculated

Unable to be calculated Unable to be calculated
due to high correlation due to high correlation

between country of

Unable to be calculated Model 2

birth \& ethnicity

between country of
birth \& ethnicity

due to high correlation 0.88

between country of
birth \& ethnicity

Sex of baby

Female
Male

1.00
$1.23(1.12,1.37) * * *$

1.00

1.00

1.00

1.00

$1.16(1.06,1.30)^{*}$

Model 3 Model 4 Model 5

Ethnicity of baby

White

1.00

1.00

1.00

1.00

1.00

Model 2 Model 4 Model 5

Asian (Bangladeshi/

Black African/

$1.86(1.62,2.15)^{* * *}$

$1.89(1.63,2.18)^{* * *}$

$1.95(1.65,2.30)^{* * *} \quad$ Equivalent to Model 2

$1.49(1.26,1.77)^{* * *}$

$1.86(1.57,2.20)^{* * *}$

6.89

$1.44(1.17,1.77)^{* *}$

$1.47(1.19,1.81)^{* * *} \quad 1.17(0.95,1.45)$

$1.09(0.88,1.36)$

$1.14(0.92,1.41)$

$1.13(0.95,1.34)$ $1.12(0.94,1.32)$

Factors on causal pathway

Birthweight (grams)

$<1,500$

$1,500-2,499$

$2,500-4,499$

$46.41(41.23,52.24)^{* * *}$

$45.55(40.46,51.29)^{* * *}$

$5.96(5.27,6.75)^{* *}$

1.00

$0.53(0.28,0.99)^{*}$

$\begin{array}{lll} & & \text { Model } 1 \\ & & 21.74 \\ \text { Interaction between } \quad \text { Interaction between } \quad \text { Interaction between } \quad \text { Interaction between } & 16.13\end{array}$

$\begin{array}{cccc}\text { Interaction between } & \begin{array}{c}\text { Interaction between } \\ \text { birthweight and }\end{array} & \begin{array}{c}\text { Interaction between } \\ \text { birthweight and }\end{array} & \begin{array}{c}\text { Interaction between } \\ \text { birthweight and }\end{array} \\ 16.13\end{array}$

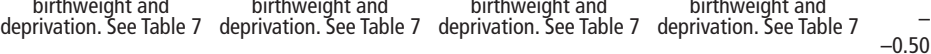

-0.50
37.37

Model 1

Gestation (weeks)

21-27

$28-31$

$32-36$

$93.40(80.95,107.76)^{* * *}$

$95.45(82.76,110.78)^{* * *}$

$17.00(14.16,20.39)^{* * *}$

$16.45(13.70,19.74)^{* * *}$

$4.76(4.17,5.43)^{* * *}$

$4.66(4.08,5.32)^{* * *}$

1.00

$0.88(0.65,1.18)$

$\begin{array}{llll}\text { Interaction between Interaction between Interaction between Interaction between } 7.07 & \end{array}$

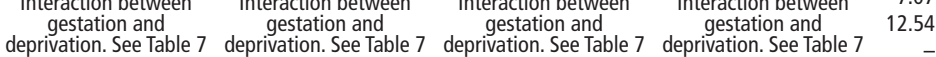

42 and over

1.00
$0.88(0.66,1.19)$

$0.88(0.65,1.18)$

Small for gestational age

SGA $(<5 \%) \quad 3.29(2.96,3.66)^{* * *}$

$3.13(2.83,3.51)^{* * *}$

Interaction between See Table 7

Interaction between A and deprivation 7
See Table

* $\mathrm{p}<0.05 \quad * * \mathrm{p}<0.005 \quad * * * \mathrm{p}<0.001$

1 Adjusted for covariate only where it is not the main explanatory variable in model.

2 Carstairs deprivation not adjusted for where NS-SEC is main explanatory variable.

3 Proportion of all deaths in population which potentially would be avoided if risk was same as that in baseline group.

4 Birth takes place outside marriage, only mother registers the birth.

5 Birth takes place outside marriage, both mother and father register the birth. 


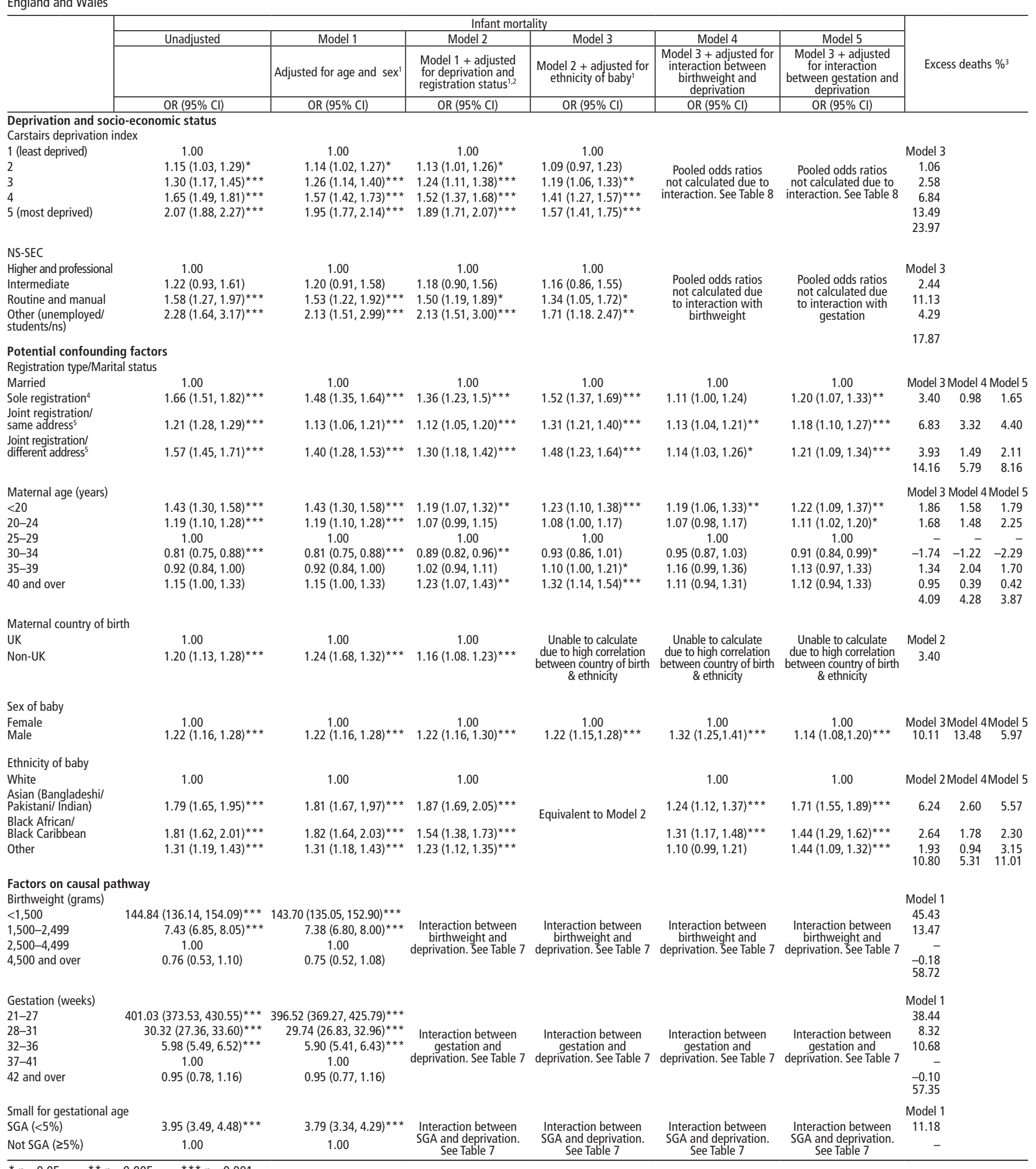

${ }^{*} \mathrm{p}<0.05 \quad{ }^{* *} \mathrm{p}<0.005 \quad{ }^{* * *} \mathrm{p}<0.001$

1 Adjusted for covariate only where it is not the main explanatory variable in model.

2 Carstairs deprivation not adjusted for where NS-SEC is main explanatory variable.

3 Proportion of all deaths in population which potentially would be avoided if risk was same as that in baseline group.

4 Birth takes place outside marriage, only mother registers the birth.

5 Birth takes place outside marriage, both mother and father register the birth. 


\begin{tabular}{|c|c|c|c|c|c|c|c|}
\hline & \multicolumn{5}{|c|}{ Carstairs deprivation index } & \multirow{3}{*}{$\begin{array}{c}\text { Total excess } \\
\text { deaths } n^{3} \\
\& \%^{4} \\
\end{array}$} & \multirow{3}{*}{$p$ value $^{2}$} \\
\hline & Quintile 1 & Quintile 2 & Quintile 3 & Quintile 4 & Quintile 5 & & \\
\hline & OR $(95 \% \mathrm{Cl})^{1}$ & OR $(95 \% \mathrm{Cl})^{1}$ & OR $(95 \% \mathrm{Cl})^{1}$ & OR $(95 \% \mathrm{Cl})^{1}$ & OR $(95 \% \mathrm{Cl})^{1}$ & & \\
\hline $\begin{array}{l}\text { Neonatal mortality } \\
\text { Birthweight } \\
\text { Low birthweight }\left(<2,500 \text { grams }^{2}\right) \\
\text { Number excess deaths per year }{ }^{3} \\
\% \text { excess deaths per year }{ }^{4}\end{array}$ & $\begin{array}{l}1.00 \\
- \\
-\end{array}$ & $\begin{array}{c}1.08(0.90,1.29) \\
12 \\
0.96\end{array}$ & $\begin{array}{c}1.13(0.96,1.35) \\
25 \\
1.96\end{array}$ & $\begin{array}{c}1.12(0.95,1.31) \\
32 \\
2.48\end{array}$ & $\begin{array}{c}1.14(0.97,1.34) \\
58 \\
4.56\end{array}$ & $\begin{array}{l}127 \\
9.96\end{array}$ & \multirow[t]{2}{*}{0.01} \\
\hline $\begin{array}{l}\text { Not low birthweight }(\geq 2,500 \text { grams}) \\
\text { Number excess deaths per year }{ }^{3} \\
\% \text { excess deaths per year }{ }^{4}\end{array}$ & $\begin{array}{l}1.00 \\
- \\
-\end{array}$ & $\begin{array}{c}0.92(0.72,1.19) \\
-6 \\
-1.22\end{array}$ & $\begin{array}{c}0.97(0.76,1.23) \\
-3 \\
-0.48\end{array}$ & $\begin{array}{c}1.31(1.05,1.64)^{*} \\
31 \\
5.84\end{array}$ & $\begin{array}{c}1.35(1.09,1.67)^{*} \\
44 \\
8.47\end{array}$ & $\begin{array}{c}66 \\
12.61\end{array}$ & \\
\hline $\begin{array}{l}\text { Gestation } \\
\text { Preterm (<37 weeks) } \\
\text { Number excess deaths per year }{ }^{3} \\
\% \text { excess deaths per year }{ }^{4}\end{array}$ & $\begin{array}{l}1.00 \\
- \\
-\end{array}$ & $\begin{array}{c}1.10(0.92,1.32) \\
15 \\
1.15\end{array}$ & $\begin{array}{c}1.18(1.00,1.40) \\
33 \\
2.59\end{array}$ & $\begin{array}{c}1.22(1.04,1.44)^{*} \\
53 \\
4.13\end{array}$ & $\begin{array}{c}1.35(1.15,1.58)^{* * *} \\
126 \\
9.74\end{array}$ & $\begin{array}{c}227 \\
17.60\end{array}$ & \multirow[t]{2}{*}{0.14} \\
\hline $\begin{array}{l}\text { Term ( } \geq 37 \text { weeks) } \\
\text { Number excess deaths per year }{ }^{3} \\
\% \text { excess deaths per year }\end{array}$ & $\begin{array}{l}1.00 \\
- \\
-\end{array}$ & $\begin{array}{c}0.93(0.72,1.20) \\
-6 \\
-1.03\end{array}$ & $\begin{array}{c}0.98(0.77,1.25) \\
-2 \\
-0.31\end{array}$ & $\begin{array}{c}1.34(1.07,1.67)^{* * *} \\
34 \\
6.34\end{array}$ & $\begin{array}{c}1.33(1.07,1.65)^{*} \\
45 \\
8.39\end{array}$ & $\begin{array}{c}72 \\
13.38\end{array}$ & \\
\hline $\begin{array}{l}\text { Small for gestational age } \\
\text { Small for gestational age }(<5 \%) \\
\text { Number excess deaths per year } \\
\% \text { excess deaths per year }\end{array}$ & $\begin{array}{l}1.00 \\
- \\
-\end{array}$ & $\begin{array}{c}0.97(0.67,1.40) \\
-1 \\
-0.32\end{array}$ & $\begin{array}{c}1.16(0.83,1.62) \\
5 \\
2.14\end{array}$ & $\begin{array}{c}1.13(0.82,1.56) \\
6 \\
2.56\end{array}$ & $\begin{array}{c}1.28(0.94,1.73) \\
23 \\
9.56\end{array}$ & $\begin{array}{c}33 \\
13.94\end{array}$ & \multirow[t]{2}{*}{0.46} \\
\hline $\begin{array}{l}\text { Not small for gestational age }(\geq 5 \%) \\
\text { Number excess deaths per year }{ }^{3} \\
\% \text { excess deaths per year }\end{array}$ & $\begin{array}{l}1.00 \\
- \\
-\end{array}$ & $\begin{array}{c}1.09(0.92,1.28) \\
16 \\
1.12\end{array}$ & $\begin{array}{c}1.17(1.00,1.38)^{*} \\
34 \\
2.41\end{array}$ & $\begin{array}{c}1.44(1.24,1.67)^{* * *} \\
105 \\
7.34\end{array}$ & $\begin{array}{c}1.43(1.32,1.78)^{* * *} \\
148 \\
10.42\end{array}$ & $\begin{array}{c}303 \\
21.28\end{array}$ & \\
\hline $\begin{array}{l}\text { Postneonatal mortality } \\
\text { Birthweight } \\
\text { Low birthweight }(<2,500 \text { grams) } \\
\text { Number excess deaths per year }{ }^{3} \\
\% \text { excess deaths per year }{ }^{4}\end{array}$ & $\begin{array}{l}1.00 \\
- \\
-\end{array}$ & $\begin{array}{c}1.13(0.81,1.57) \\
6 \\
1.51\end{array}$ & $\begin{array}{c}1.00(0.73,1.38) \\
- \\
-\end{array}$ & $\begin{array}{c}1.04(0.77,1.40) \\
3 \\
0.93\end{array}$ & $\begin{array}{c}1.00(0.75,1.33) \\
- \\
-\end{array}$ & $\begin{array}{c}9 \\
2.45\end{array}$ & \multirow[t]{2}{*}{$<0.001$} \\
\hline $\begin{array}{l}\text { Not low birthweight ( } \geq 2,500 \text { grams }) \\
\text { Number excess deaths per year }{ }^{3} \\
\% \text { excess deaths per year }\end{array}$ & $\begin{array}{l}1.00 \\
- \\
-\end{array}$ & $\begin{array}{c}1.12(0.85,1.47) \\
7 \\
1.32\end{array}$ & $\begin{array}{c}1.21(0.93,1.57) \\
15 \\
2.84\end{array}$ & $\begin{array}{c}1.44(1.12,1.84)^{*} \\
36 \\
7.01\end{array}$ & $\begin{array}{c}1.83(1.44,2.32)^{* * *} \\
88 \\
17.17\end{array}$ & $\begin{array}{c}145 \\
28.34\end{array}$ & \\
\hline $\begin{array}{l}\text { Gestation } \\
\text { Preterm (<37 weeks) } \\
\text { Number excess deaths per year }{ }^{3} \\
\% \text { excess deaths per year }{ }^{4}\end{array}$ & $\begin{array}{l}1.00 \\
- \\
-\end{array}$ & $\begin{array}{c}1.22(0.88,1.75) \\
8 \\
2.43\end{array}$ & $\begin{array}{c}1.15(0.82,1.61) \\
7 \\
2.09\end{array}$ & $\begin{array}{c}1.27(0.93,1.74) \\
18 \\
5.31\end{array}$ & $\begin{array}{c}1.23(0.91,1.67) \\
22 \\
6.80\end{array}$ & $\begin{array}{c}55 \\
16.64\end{array}$ & \multirow[t]{2}{*}{0.03} \\
\hline $\begin{array}{l}\text { Term ( } \geq 37 \text { weeks) } \\
\text { Number excess deaths per year }{ }^{3} \\
\% \text { excess deaths per year }{ }^{4}\end{array}$ & $\begin{array}{l}1.00 \\
- \\
-\end{array}$ & $\begin{array}{c}1.08(0.83,1.41) \\
5 \\
0.90\end{array}$ & $\begin{array}{c}1.12(0.87,1.45) \\
9 \\
1.68\end{array}$ & $\begin{array}{c}1.34(1.06,1.71)^{*} \\
31 \\
5.73\end{array}$ & $\begin{array}{c}1.68(1.34,2.12)^{* * *} \\
86 \\
15.72\end{array}$ & $\begin{array}{c}131 \\
24.04\end{array}$ & \\
\hline $\begin{array}{l}\text { Small for gestational age } \\
\text { Small for gestational age }(<5 \%) \\
\text { Number excess deaths per year } \\
\% \text { excess deaths per year }\end{array}$ & $\begin{array}{l}1.00 \\
- \\
-\end{array}$ & $\begin{array}{c}1.00(0.66,1.52) \\
- \\
-\end{array}$ & $\begin{array}{c}0.73(0.48,1.10) \\
-8 \\
-5.14\end{array}$ & $\begin{array}{c}0.95(0.65,1.37) \\
-2 \\
-1.18\end{array}$ & $\begin{array}{c}0.99(0.69,1.40) \\
-1 \\
-0.44\end{array}$ & $\begin{array}{c}-10 \\
-6.76\end{array}$ & \multirow[t]{2}{*}{0.02} \\
\hline $\begin{array}{l}\text { Not small for gestational age }(\geq 5 \%) \\
\text { Number excess deaths per year }{ }^{3} \\
\% \text { excess deaths per year }\end{array}$ & $\begin{array}{l}1.00 \\
- \\
-\end{array}$ & $\begin{array}{c}1.18(0.92,1.50) \\
14 \\
1.98\end{array}$ & $\begin{array}{c}1.39(1.03,1.64)^{*} \\
33 \\
4.55\end{array}$ & $\begin{array}{c}1.49(1.19,1.86)^{* * *} \\
57 \\
7.80\end{array}$ & $\begin{array}{c}1.76(1.42,2.18)^{* * *} \\
116 \\
15.89\end{array}$ & $\begin{array}{c}220 \\
30.23\end{array}$ & \\
\hline $\begin{array}{l}\text { Infant mortality } \\
\text { Birthweight } \\
\text { Low birthweight }(<2,500 \text { grams) } \\
\text { Number excess deaths per year }{ }^{3} \\
\% \text { excess deaths per year }\end{array}$ & $\begin{array}{l}1.00 \\
- \\
-\end{array}$ & $\begin{array}{c}1.09(0.93,1.28) \\
18 \\
1.07\end{array}$ & $\begin{array}{c}1.10(0.94,1.28) \\
25 \\
1.51\end{array}$ & $\begin{array}{c}1.09(0.94,1.25) \\
32 \\
1.93\end{array}$ & $\begin{array}{c}1.09(0.93,1.25) \\
50 \\
3.08\end{array}$ & $\begin{array}{l}125 \\
7.60\end{array}$ & \multirow[t]{2}{*}{$<0.001$} \\
\hline $\begin{array}{l}\text { Not low birthweight }(\geq 2,500 \text { grams}) \\
\text { Number excess deaths per year } \\
\% \text { excess deaths per year }{ }^{3}\end{array}$ & $\begin{array}{l}1.00 \\
- \\
-\end{array}$ & $\begin{array}{c}1.01(0.84,1.22) \\
1 \\
0.13\end{array}$ & $\begin{array}{c}1.08(0.91,1.29) \\
12 \\
1.18\end{array}$ & $\begin{array}{c}1.39(1.18,1.63)^{* * *} \\
69 \\
6.68\end{array}$ & $\begin{array}{c}1.60(1.37,1.88)^{* * *} \\
137 \\
13.21\end{array}$ & $\begin{array}{c}220 \\
21.20\end{array}$ & \\
\hline $\begin{array}{l}\text { Gestation } \\
\text { Preterm (<37 weeks) } \\
\text { Number excess deaths per year } \\
\% \text { excess deaths per year }{ }^{4}\end{array}$ & $\begin{array}{l}1.00 \\
- \\
-\end{array}$ & $\begin{array}{c}1.13(0.96,1.33) \\
24 \\
1.48\end{array}$ & $\begin{array}{c}1.17(1.01,1.36)^{*} \\
40 \\
2.44\end{array}$ & $\begin{array}{c}1.22(1.06,1.42)^{*} \\
68 \\
4.20\end{array}$ & $\begin{array}{c}1.31(1.14,1.51)^{* * *} \\
143 \\
8.83\end{array}$ & $\begin{array}{c}275 \\
16.95\end{array}$ & \multirow[t]{2}{*}{0.007} \\
\hline $\begin{array}{l}\text { Term ( } \geq 37 \text { weeks) } \\
\text { Number excess deaths per year } \\
\% \text { excess deaths per year }{ }^{4}\end{array}$ & $\begin{array}{l}1.00 \\
- \\
-\end{array}$ & $\begin{array}{c}1.00(0.83,1.20) \\
- \\
-\end{array}$ & $\begin{array}{c}1.05(0.88,1.26) \\
8 \\
0.74\end{array}$ & $\begin{array}{c}1.36(1.15,1.60)^{* * *} \\
68 \\
6.29\end{array}$ & $\begin{array}{c}1.53(1.30,1.78)^{* * *} \\
136 \\
12.59\end{array}$ & $\begin{array}{c}212 \\
19.62\end{array}$ & \\
\hline $\begin{array}{l}\text { Small for gestational age } \\
\text { Small for gestational age }(<5 \%) \\
\text { Number excess deaths per year } \\
\% \text { excess deaths per year }{ }^{4}\end{array}$ & $\begin{array}{l}1.00 \\
- \\
-\end{array}$ & $\begin{array}{c}0.98(0.75,1.30) \\
-0.1 \\
-0.22\end{array}$ & $\begin{array}{c}0.97(0.75,1.26) \\
-2 \\
-0.46\end{array}$ & $\begin{array}{c}1.05(0.82,1.34) \\
4 \\
1.06\end{array}$ & $\begin{array}{c}1.15(0.92,1.45) \\
22 \\
5.68\end{array}$ & $\begin{array}{c}23 \\
6.07\end{array}$ & \multirow[t]{2}{*}{0.06} \\
\hline $\begin{array}{l}\text { Not small for gestational age }(\geq 5 \%) \\
\text { Number excess deaths per year }{ }^{3} \\
\% \text { excess deaths per year }{ }^{4}\end{array}$ & $\begin{array}{l}1.00 \\
- \\
-\end{array}$ & $\begin{array}{c}1.11(0.97,1.28) \\
-28 \\
-1.32\end{array}$ & $\begin{array}{c}1.22(1.07,1.39)^{*} \\
64 \\
2.97\end{array}$ & $\begin{array}{c}1.45(1.28,1.65)^{* * *} \\
160 \\
7.42\end{array}$ & $\begin{array}{c}1.60(1.42,1.81)^{* * *} \\
285 \\
13.26\end{array}$ & $\begin{array}{c}480 \\
22.33\end{array}$ & \\
\hline
\end{tabular}

${ }^{*} \mathrm{p}<0.05 \quad{ }^{* *} \mathrm{p}<0.005 \quad{ }^{* * *} \mathrm{p}<0.001$

1 Adjusted for maternal age, registration status, sex of child and ethnicity of child.

2 P value from interaction taken from likelihood ratio test.

3 Number of deaths in sub-population (eg low birthweight babies) which potentially would be avoided each year if deprivation level was 1 . Adjusted for maternal age, registration status, sex of child and ethnicity of child.

4 Proportion of deaths in sub-population (eg low birthweight babies) which potentially would be avoided each year if deprivation level was 1 . Adjusted for maternal age, registration status, sex of child and ethnicity of child. 
Adjusted odds ratios for the effect of low birthweight, preterm and small for gestational age on neonatal, postneonatal and infant mortality, stratified by deprivation, 2005-06.

Population excess deaths (number and proportion) attributed to low birthweight, preterm delivery and small gestation for age also presented.

England and Wales

\begin{tabular}{|c|c|c|c|c|c|c|c|c|c|c|c|c|c|c|c|}
\hline \multirow{3}{*}{$\begin{array}{l}\text { Carstairs } \\
\text { deprivation } \\
\text { index }\end{array}$} & \multicolumn{5}{|c|}{ Birthweight } & \multicolumn{5}{|c|}{ Gestation } & \multicolumn{5}{|c|}{ Small for gestational age } \\
\hline & \multirow{2}{*}{\begin{tabular}{|c|} 
Not low \\
birthweight \\
$(\geq 2,500$ \\
grams) \\
\\
\\
OR \\
$\left.95 \% \mathrm{Cl}^{1}\right)$
\end{tabular}} & \multicolumn{4}{|c|}{ Low birthweight $(<2,500$ grams) } & \multirow{2}{*}{$\begin{array}{c}\text { Term } \\
(\geq 37 \\
\text { weeks) } \\
\\
\text { OR } \\
(95 \% \\
\mathrm{Cl})^{1}\end{array}$} & \multicolumn{4}{|c|}{ Preterm (<37 weeks) } & \multirow{2}{*}{$\begin{array}{c}\text { Not } \\
\text { small for } \\
\text { gestational } \\
\text { age }(\geq 5 \%) \\
\\
\text { OR } \\
(95 \% \mathrm{Cl})^{1}\end{array}$} & \multicolumn{4}{|c|}{ Small for gestational age $(<5 \%)$} \\
\hline & & OR $(95 \% \mathrm{Cl}) 1$ & $p$ value $^{2}$ & $\begin{array}{c}\text { Number } \\
\text { of excess } \\
\text { deaths } \\
\text { per year }\end{array}$ & $\left|\begin{array}{c}\% \text { excess } \\
\text { deaths } \\
\text { per year }\end{array}\right|$ & & $\begin{array}{c}\text { OR } \\
(95 \% \mathrm{Cl})^{1}\end{array}$ & $p$ value ${ }^{2}$ & \begin{tabular}{|c|} 
Number \\
excess \\
deaths \\
per year ${ }^{3}$
\end{tabular} & $\begin{array}{c}\% \text { excess } \\
\text { deaths } \\
\text { per year }\end{array}$ & & $\begin{array}{c}\text { OR } \\
(95 \% \mathrm{Cl})^{1}\end{array}$ & p value ${ }^{2}$ & \begin{tabular}{|c|} 
Number \\
excess \\
deaths \\
per year
\end{tabular} & $\begin{array}{c}\% \text { excess } \\
\text { deaths } \\
\text { per year }\end{array}$ \\
\hline \multicolumn{16}{|c|}{ Neonatal mortality } \\
\hline 1 (least deprived) & 1.00 & $39.40(31.52,49.24)$ & & 121 & 62.71 & 1.00 & $35.00(27.93,43.84)$ & & 124 & 64.09 & 1.00 & $3.25(2.23,4.75)$ & & 12 & 7.37 \\
\hline 2 & 1.00 & $45.96(37.13,56.89)$ & & 161 & 67.68 & 1.00 & $41.67(33.60,51.67)$ & & 160 & 67.25 & 1.00 & $2.96(2.13,4.11)$ & & 17 & 7.59 \\
\hline 3 & 1.00 & $46.39(38.28,56.22)$ & $<0.01$ & 213 & 71.22 & 1.00 & $42.25(34.88,51.18)$ & 0.14 & 214 & 71.04 & 1.00 & $3.28(2.52,4.27)$ & 0.7 & 26 & 9.40 \\
\hline 4 & 1.00 & $33.44(28.64,39.04)$ & & 288 & 67.52 & 1.00 & $32.05(27.50,37.34$ & & 286 & 68.72 & 1.00 & $2.68(2.16,3.33)$ & & 33 & 8.40 \\
\hline 5 (most deprived) & 1.00 & $33.16(29.06,37.84)$ & & 460 & 71.24 & 1.00 & $35.34(31.11,40.16)$ & & 471 & 70.66 & 1.00 & $2.73(2.33,3.19)$ & & 66 & 11.03 \\
\hline \multicolumn{16}{|c|}{ Postneonatal mortality } \\
\hline 1 (least deprived) & 1.00 & $14.49(10.48,20.02)$ & & 32 & 35.97 & 1.00 & $10.13(7.28,14.09)$ & & 27 & 30.73 & 1.00 & $5.40(3.49,8.36)$ & & 11 & 12.50 \\
\hline 2 & 1.00 & $14.65(11.08,19.38)$ & & 45 & 40.32 & 1.00 & $11.68(8.82,15.47)$ & & 41 & 36.66 & 1.00 & $4.13(2.80,6.10)$ & & 13 & 11.27 \\
\hline 3 & 1.00 & $12.04(9.34,15.50)$ & $<0.001$ & 50 & 36.28 & 1.00 & $10.39(8.05,13.41)$ & 0.03 & 48 & 34.58 & 1.00 & $3.31(2.30,4.76)$ & 0.11 & 14 & 10.33 \\
\hline 4 & 1.00 & $10.48(8.53,12.87)$ & & 80 & 38.85 & 1.00 & $9.60(7.81,11.81)$ & & 74 & 35.96 & 1.00 & $3.15(2.39,4.17)$ & & 23 & 10.96 \\
\hline 5 (most deprived) & 1.00 & $7.91(6.72,9.31)$ & & 121 & 36.46 & 1.00 & $7.40(6.27,8.74)$ & & 104 & 31.31 & 1.00 & $2.88(2.35,3.53)$ & & 42 & 12.60 \\
\hline \multicolumn{16}{|l|}{ Infant mortality } \\
\hline 1 (least deprived) & 1.00 & $28.73(24.00,34.39)$ & & 153 & 54.35 & 1.00 & $23.59(19.72,28.23)$ & & 151 & 53.65 & 1.00 & $3.96(2.98,5.27)$ & & 24 & 9.12 \\
\hline 2 & 1.00 & $30.87(26.18,36.39)$ & & 206 & 58.97 & 1.00 & $26.65(22.62,31.41)$ & & 201 & 57.50 & 1.00 & $3.38(2.62,4.34)$ & & 29 & 8.88 \\
\hline 3 & 1.00 & $29.19(15.20,33.80)$ & $<0.001$ & 264 & 60.12 & 1.00 & $26.18(22.61,30.30)$ & $<0.01$ & 262 & 58.20 & 1.00 & $3.30(2.66,4.08)$ & 0.16 & 40 & 9.73 \\
\hline 4 & 1.00 & $22.48(19.93,25.35)$ & & 368 & 58.12 & 1.00 & $21.32(18.93,24.01)$ & & 360 & 56.69 & 1.00 & $2.85(2.40,3.38)$ & & 56 & 9.30 \\
\hline 5 (most deprived) & 1.00 & $19.46(17.65,21.45)$ & & 582 & 59.45 & 1.00 & $20.25(18.41,22.27)$ & & 575 & 57.60 & 1.00 & $2.79(2.46,3.16)$ & & 108 & 11.60 \\
\hline
\end{tabular}

1 Adjusted for maternal age, registration status, sex of child and ethnicity of child.

2 P value from interaction taken from likelihood ratio test.

3 Number of deaths in sub-population (for example, Carstairs deprivation level 5) which potentially could be avoided each year if all babies had risk of that in the baseline group, adjusted for maternal age, registration status, sex of child and ethnicity of child.

4 Proportion of deaths in sub-population (for example, Carstairs deprivation level 5) which potentially would be avoided each year if all babies had risk of that in the baseline group, adjusted for maternal age, registration status, sex of child and ethnicity of child. 


\section{Appendix}

\section{Table A1}

Covariates by Carstairs distribution, 2005-06

England and Wales

\begin{tabular}{|c|c|c|c|c|c|c|c|c|c|c|c|c|c|c|}
\hline & \multicolumn{10}{|c|}{ Carstairs quintiles } & \multirow{3}{*}{\begin{tabular}{|l|} 
Missing \\
Number \\
\end{tabular}} & \multirow{2}{*}{\multicolumn{2}{|c|}{ All }} \\
\hline & & \multicolumn{2}{|c|}{$\begin{array}{l}\text { Quintile } 1 \text { (least } \\
\text { deprived) }\end{array}$} & \multicolumn{2}{|c|}{ Quintile 2} & \multicolumn{2}{|c|}{ Quintile 3} & \multicolumn{2}{|c|}{ Quintile 4} & \multicolumn{2}{|c|}{$\begin{array}{c}\text { Quintile } 5 \text { (most } \\
\text { deprived) }\end{array}$} & & & \\
\hline & & Number & \begin{tabular}{l|}
$\%$ non- \\
missing
\end{tabular} & Number & \begin{tabular}{|c|}
$\%$ non- \\
missing
\end{tabular} & Number & \begin{tabular}{|c|}
$\%$ non- \\
missing
\end{tabular} & Number & \begin{tabular}{|c|}
$\%$ non- \\
missing
\end{tabular} & Number & \begin{tabular}{l|}
$\%$ non- \\
missing
\end{tabular} & & Number & $\begin{array}{l}\% \text { non- } \\
\text { missing }\end{array}$ \\
\hline \multirow[t]{2}{*}{ Year } & 2005 & 98,318 & 49.3 & 105,261 & 49.3 & 117,779 & 49.2 & 135,268 & 49.0 & 170,096 & 49.0 & 195 & 626,917 & 49.1 \\
\hline & 2006 & 101,222 & 50.7 & 108,352 & 50.7 & 121,562 & 50.8 & 140,864 & 51.0 & 177,086 & 51.0 & 195 & 649,281 & 50.9 \\
\hline \multirow[t]{4}{*}{ Registration type/Marital status } & Married & 144,080 & 72.2 & 136,222 & 63.8 & 133,228 & 55.7 & 132,276 & 47.9 & 176,787 & 50.9 & 278 & 722,871 & 56.6 \\
\hline & Sole registration & 5,029 & 2.5 & 8,637 & 4.0 & 13,914 & 5.8 & 23,338 & 8.5 & 37,301 & 10.7 & 23 & 88,242 & 6.9 \\
\hline & Joint registration/same address & 43,420 & 21.8 & 57,082 & 26.7 & 73,404 & 30.7 & 89,604 & 32.4 & 87,852 & 25.3 & 67 & 351,429 & 27.5 \\
\hline & Joint registration/different address & 7,011 & 3.5 & 11,672 & 5.5 & 18,795 & 7.9 & 30,914 & 11.2 & 45,242 & 13.0 & 22 & 113,656 & 8.9 \\
\hline \multirow[t]{6}{*}{ Maternal age (years) } & $<20$ & 5,289 & 2.7 & 9,513 & 4.5 & 15,599 & 6.5 & 25,030 & 9.1 & 33,664 & 9.7 & 13 & 89,108 & 7.0 \\
\hline & $20-24$ & 17,870 & 9.0 & 28,116 & 13.2 & 43,220 & 18.1 & 63,765 & 23.1 & 92,294 & 26.6 & 63 & 245,328 & 19.2 \\
\hline & $25-29$ & 40,866 & 20.5 & 52,185 & 24.4 & 62,980 & 26.3 & 75,030 & 27.2 & 96,928 & 27.9 & 113 & 328,102 & 25.7 \\
\hline & $30-34$ & 75,286 & 37.7 & 72,904 & 34.1 & 71,337 & 29.8 & 68,952 & 25.0 & 75.669 & 21.8 & 101 & 364,249 & 28.5 \\
\hline & $35-39$ & 49,631 & 24.9 & 42,258 & 19.8 & 38,476 & 16.1 & 35,785 & 13.0 & 39,409 & 11.4 & 74 & 205,633 & 16.1 \\
\hline & 40 and over & 10,597 & 5.3 & 8,637 & 4.0 & 7,729 & 3.2 & 7,570 & 2.7 & 9,218 & 2.7 & 26 & 43,777 & 3.4 \\
\hline \multirow[t]{2}{*}{ Sex of baby } & Male & 102,114 & 51.2 & 109,651 & 51.3 & 123,009 & 51.4 & 140,892 & 51.0 & 177,493 & 51.1 & 203 & 653,362 & 51.2 \\
\hline & Female & 97,426 & 48.8 & 103,962 & 48.7 & 116,332 & 48.6 & 135,240 & 49.0 & 169,689 & 48.9 & 187 & 622,836 & 48.8 \\
\hline \multirow[t]{5}{*}{ Ethnicity of baby } & White & 162,820 & 92.3 & 168,370 & 89.3 & 183,744 & 86.2 & 198,483 & 79.3 & 175,629 & 56.0 & 195 & 889,241 & 77.8 \\
\hline & Asian & 3,584 & 2.0 & 6,185 & 3.3 & 9,600 & 4.5 & 16,482 & 6.6 & 61,046 & 19.5 & 11 & 96,908 & 8.5 \\
\hline & Black & 1,282 & 0.7 & 2,403 & 1.3 & 4,538 & 2.1 & 11,758 & 4.7 & 34,005 & 10.8 & 13 & 53,999 & 4.7 \\
\hline & Other & 8,626 & 4.9 & 11,621 & 6.2 & 15,204 & 7.1 & 23,486 & 9.4 & 43,164 & 13.8 & 32 & 102,133 & 8.9 \\
\hline & Missing & 23,228 & 13.2 & 25,034 & 13.3 & 26,255 & 12.3 & 25,923 & 10.4 & 33,338 & 10.6 & 139 & 133,917 & 11.7 \\
\hline \multirow{10}{*}{$\begin{array}{l}\text { Baby's ethnicity and maternal } \\
\text { county of birth }\end{array}$} & & & & & & & & & & & & & & \\
\hline & White, UK born & 149,746 & 84.9 & 155,085 & 82.2 & 170,002 & 79.8 & 183,026 & 73.2 & 154,693 & 49.3 & 150 & 812,702 & 71.1 \\
\hline & White, non-UK born & 13,071 & 7.4 & 13,280 & 7.0 & 13,740 & 6.4 & 15,453 & 6.2 & 20,928 & 6.7 & 45 & 76,517 & 6.7 \\
\hline & Asian, UK born & 1,469 & 0.8 & 2,266 & 1.2 & 3,298 & 1.5 & 5,522 & 2.2 & 19,645 & 6.3 & 3 & 32,203 & 2.8 \\
\hline & Asian, non-UK born & 2,115 & 1.2 & 3,919 & 2.1 & 6,302 & 3.0 & 10,960 & 4.4 & 41,396 & 13.2 & 8 & 64,700 & 5.7 \\
\hline & Black, UK born & 324 & 0.2 & 561 & 0.3 & 1,040 & 0.5 & 2,855 & 1.1 & 7,212 & 2.3 & - & 11,992 & 1.0 \\
\hline & Black, non-UK born & 958 & 0.5 & 1,842 & 1.0 & 3,498 & 1.6 & 8,903 & 3.6 & 26,790 & 8.5 & 13 & 42,004 & 3.7 \\
\hline & Other, UK born & 4,064 & 2.3 & 5,271 & 2.8 & 6,608 & 3.1 & 10,037 & 4.0 & 16,110 & 5.1 & 3 & 42,093 & 3.7 \\
\hline & Other, non-UK born & 4,561 & 2.6 & 6,350 & 3.4 & 8,596 & 4.0 & 13,449 & 5.4 & 27,053 & 8.6 & 28 & 60,037 & 5.3 \\
\hline & Missing (not stated/not linked) & 23,232 & & 25,039 & & 26,257 & & 25,927 & & 33,355 & & 140 & 133,950 & \\
\hline Birthweight (grams) & $<1,500$ & 1,297 & 0.7 & 1,641 & 0.8 & 2,067 & 0.9 & 2,814 & 1.0 & 4,282 & 1.2 & 31 & 12,132 & 1.0 \\
\hline & $1,500-2,499$ & 7,156 & 3.6 & 8,628 & 4.1 & 10,924 & 4.6 & 15,163 & 5.5 & 23,146 & 6.7 & 33 & 65,050 & 5.1 \\
\hline & $2,500-4,499$ & 186,320 & 93.6 & 198,140 & 93.2 & 220,978 & 92.7 & 252,110 & 91.8 & 311,550 & 90.7 & 317 & $1,169,415$ & 92.2 \\
\hline & 4,500 and over & 4,200 & 2.1 & 4,239 & 2.0 & 4,364 & 1.8 & 4,524 & 1.6 & 4,378 & 1.3 & 4 & 21,709 & 1.7 \\
\hline & Missing & 567 & & 965 & & 1,008 & & 1,521 & & 3,826 & & 5 & 7,892 & \\
\hline Low birthweight & Yes & 8,453 & 4.2 & 10,269 & 4.8 & 12,991 & 5.5 & 17,977 & 6.5 & 27,428 & 8.0 & 64 & 77,182 & 6.1 \\
\hline & No & 190,520 & 95.8 & 202,379 & 95.2 & 225,342 & 94.5 & 256,634 & 93.5 & 315,928 & 92.0 & 321 & $1,191,124$ & 93.9 \\
\hline & Missing & 567 & & 965 & & 1,008 & & 1,521 & & 3,826 & & 5 & 7,892 & \\
\hline Gestation (weeks) & $21-27$ & 491 & 0.2 & 658 & 0.3 & 816 & 0.3 & 1,161 & 0.4 & 1,791 & 0.5 & 17 & 4,934 & 0.4 \\
\hline & $28-31$ & 1,072 & 0.5 & 1,277 & 0.6 & 1,507 & 0.6 & 2,009 & 0.7 & 2,985 & 0.9 & 16 & 8,866 & 0.7 \\
\hline & $32-36$ & 8,576 & 4.3 & 9,639 & 4.5 & 11,698 & 4.9 & 14,708 & 5.4 & 19,673 & 5.7 & 36 & 64,330 & 5.1 \\
\hline & $37-41$ & 179,690 & 90.5 & 191,555 & 90.1 & 213,682 & 89.7 & 243,796 & 88.9 & 302,815 & 88.5 & 306 & $1,131,844$ & 89.4 \\
\hline & 42 and over & 8,726 & 4.4 & 9,407 & 4.4 & 10,513 & 4.4 & 12,601 & 4.6 & 15,008 & 4.4 & 5 & 56,260 & 4.4 \\
\hline & Missing (inconsistent gest-bwt) & 19 & & 25 & & 31 & & 46 & & 65 & & 1 & 187 & \\
\hline & Missing (gest not stated) & 804 & & 889 & & 885 & & 1,507 & & 4,339 & & 2 & 8,426 & \\
\hline & Missing (no link to nn4b) & 162 & & 163 & & 209 & & 304 & & 506 & & 7 & 1,351 & \\
\hline & Missing & 985 & & 1,077 & & 1,125 & & 1,857 & & 4,910 & & 10 & 9,964 & \\
\hline Preterm & Yes & 10,139 & 5.1 & 11,574 & 5.4 & 14,021 & 5.9 & 17,878 & 6.5 & 24,449 & 7.1 & 69 & 78,130 & 6.2 \\
\hline & No & 188,416 & 94.9 & 200,962 & 94.6 & 224,195 & 94.1 & 256,397 & 93.5 & 317,823 & 92.9 & 311 & $1,188,104$ & 93.8 \\
\hline & Missing & 985 & & 1,077 & & 1,125 & & 1,857 & & 4,910 & & 10 & 9,964 & \\
\hline Small for gestational age & $\operatorname{SGA}(<5 \%)$ & 6,076 & 3.1 & 7,873 & 3.7 & 10,026 & 4.2 & 14,133 & 5.2 & 24,017 & 7.0 & 11 & 62,136 & 4.9 \\
\hline & Not SGA $(\geq 5 \%)$ & 192,446 & 96.9 & 204,623 & 96.3 & 228,135 & 95.8 & 260,070 & 94.8 & 318,115 & 93.0 & 367 & $1,203,756$ & 95.1 \\
\hline & Missing & 1,018 & & 1,117 & & 1,180 & & 1,929 & & 5,050 & & 12 & 10,306 & \\
\hline
\end{tabular}

